NBER WORKING PAPER SERIES

\title{
POLITICAL VIOLENCE, RISK AVERSION, AND NON-LOCALIZED DISEASE SPREAD: EVIDENCE FROM THE U.S. CAPITOL RIOT
}

\author{
Dhaval M. Dave \\ Drew McNichols \\ Joseph J. Sabia \\ Working Paper 28410 \\ http://www.nber.org/papers/w28410 \\ NATIONAL BUREAU OF ECONOMIC RESEARCH \\ 1050 Massachusetts Avenue \\ Cambridge, MA 02138 \\ February 2021
}

We thank Kyutaro Matsuzawa and Samuel Safford for excellent research assistance on this paper. This research was supported by the Center for Health Economics \& Policy Studies (CHEPS), which has received grant funding from the Charles Koch Foundation and the Troesh Family Foundation. The views expressed herein are those of the authors and do not necessarily reflect the views of the National Bureau of Economic Research.

NBER working papers are circulated for discussion and comment purposes. They have not been peer-reviewed or been subject to the review by the NBER Board of Directors that accompanies official NBER publications.

(C) 2021 by Dhaval M. Dave, Drew McNichols, and Joseph J. Sabia. All rights reserved. Short sections of text, not to exceed two paragraphs, may be quoted without explicit permission provided that full credit, including $(\odot$ notice, is given to the source. 
Political Violence, Risk Aversion, and Non-Localized Disease Spread: Evidence from the U.S. Capitol Riot

Dhaval M. Dave, Drew McNichols, and Joseph J. Sabia

NBER Working Paper No. 28410

February 2021

JEL No. D8,H75,I1

\section{$\underline{\text { ABSTRACT }}$}

On January 6, 2021, the U.S. Capitol was sieged by rioters protesting certification of Joseph R. Biden's election as the 46th president of the United States. The Director of the Centers for Disease Control and Prevention (CDC) quickly predicted that the Riot would be a COVID-19 "surge event." This study is the first to estimate the impact of the Capitol Riot on risk-averting behavior and community-level spread of the novel coronavirus. First, using anonymized smartphone data from SafeGraph, Inc. and an event-study approach, we document that on January 6th there was a substantial increase in non-resident smartphone pings in the census block groups including the Ellipse, the National Mall, and the U.S. Capitol Building, consistent with a large protest that day. Next, using data from the same source and a synthetic control approach, we find that the Capitol Riot increased stay-at-home behavior among District of Columbia residents, indicative of risk averting behaviors in response to violence and health risks. Finally, turning to COVID-19 case data, we find no evidence that the Capitol Riot substantially increased community spread of COVID-19 in the District of Columbia in the month-long period following the event. This may be due to increases in social distancing and a "virtual lockdown" of the Capitol prior to the inauguration of the new president. However, exploiting variation in nonresident smartphone inflows into the January 6 Capitol protest, we find that counties with the highest protester inflows experienced a significant increase in the rate of daily cumulative COVID-19 case growth in the month following the protest. We conclude that the Capitol Riot may have contributed to non-localized COVID-19 spread.

Dhaval M. Dave

Bentley University

Department of Economics

175 Forest Street, AAC 195

Waltham, MA 02452-4705

and IZA

and also NBER

ddave@bentley.edu

Drew McNichols

San Diego State University

Center for Health Economics

$\&$ Policy Studies

5500 Campanile Drive

San Diego, CA 92182

dmcnichols@ucsd.edu
Joseph J. Sabia

San Diego State University

Department of Economics

Center for Health Economics

$\&$ Policy Studies

5500 Campanile Drive

San Diego, CA 92182

and IZA \& ESSPRI

jsabia@sdsu.edu 


\section{Motivation}

"I do think you have to anticipate that this is another [COVID-19] surge event...You had largely unmasked individuals in a non-distanced fashion, who were all through the Capitol. Then these individuals all are going in cars and trains and planes going home all across the country. So this is an event that is going to have public health consequences.”

- Center for Disease Control and Prevention Director Robert Redfield, January 11, 2021

On January 6, 2021, thousands of supporters of President Donald J. Trump gathered in Washington, D.C. to protest the U.S. Congress's certification of Joseph R. Biden's election as the $46^{\text {th }}$ president of the United States. The protest was part of a series of so-called Stop the Steal events held throughout the country following the November 4, 2020 elections. Organized by right-wing populist activists, the January rally was designed to delegitimize President Biden’s election with claims — largely unsubstantiated in state and Federal courts — of widespread voter fraud (Sardarizadeh and Lussenhop 2021).

During the early afternoon hours, President Trump delivered a speech on the Ellipse near the White House in which he urged protesters to "take back our country":

“We fight like Hell and if you don’t fight like Hell, you're not going to have a country anymore... So we're going to, we're going to walk down Pennsylvania Avenue, I love Pennsylvania Avenue, and we're going to the Capitol and we're going to try and give...our Republicans, the weak ones, because the strong ones don't need any of our help, we're going to try and give them the kind of pride and boldness that they need to take back our country. So let’s walk down Pennsylvania Avenue.” (Donald J. Trump, January 6, 2021) 
While President Trump never joined the crowd of protesters, and some media reports suggest that the Capitol attack was planned by some days in advance (Hsu, Jackman, and Barrett 2021), thousands did heed his call and marched to the Capitol Building. There, the violent intentions of many rioters became known through their physical assaults on Capitol police, penetration of multiple police barricades, and destruction of property in the U.S. Capitol Building (Peñaloza 2021). During what the U.S. House of Representatives deemed an “insurrection” (Fandos and Cochrane 2021), five individuals, including a Capitol police officer, were killed (Safdar, Ailworth and Seetharaman 2021). In addition, it was learned that domestic terrorists connected to the Rally planted pipe bombs around locations throughout the District of Columbia, including at headquarters of the Republican and Democrat National Committees (Balsamo 2021).

By the afternoon of the Rally, rioters gained access to the Senate and House chambers and successfully (albeit temporarily) stopped the certification of President Biden's election (Shear 2021). By evening the Capitol Police had gained control of the U.S. Capitol and President Biden’s election was certified (Fandos and Cochrane 2021). In the wake of the Riot, nearly 20,000 National Guard troops were deployed to restore order for President Biden’s inauguration (Booker 2021). The near lockdown of the Capitol area continued for many weeks. As of February 11, 188 individuals involved in the Riot were charged with Federal crimes (United States Department of Justice 2021).

Denunciation of the Capitol Riot was swift and bipartisan, as was criticism of President Trump, in not only failing to quell the violence, but also for fanning the flames of political discord (Leary 2021). As a result, on January 13, 2021, President Trump became the first U.S. 
president to be impeached twice. Article 1 of the House of Representatives' articles of impeachment was titled “Incitement of Insurrection”:

"[I]ncited by President Trump, members of the crowd he had addressed, in an attempt to, among other objectives, interfere with the Joint Session's solemn constitutional duty to certify the results of the 2020 Presidential election, unlawfully breached and vandalized the Capitol, injured and killed law enforcement personnel, menaced Members of Congress, the Vice President, and Congressional personnel, and engaged in other violent, deadly, destructive and seditious acts." (U.S. House of Representatives, Article of Impeachment Against President Donald J. Trump, January 13, 2021)

While much of the public discussion surrounding the Capitol Riot concerns its effects on democracy and national unity during the peaceful transition of executive power, public health officials have warned of another threat from the Riot: a surge of COVID-19 infections (Ellis 2021). In early January, the United States was in the midst of one of the worst periods of contagion since the onset of the pandemic (Zraick and Robbins 2021). While the 7-day average of U.S. coronavirus cases during the summer of 2020 was below 100,000, the COVID-19 daily case rate more than doubled to 200,000 per week by early 2021, with over 25 million confirmed COVID-19 cases and nearly 420,000 COVID-19-related deaths by January 25 (Centers for Disease Control and Prevention 2021). In Washington, D.C., the rate of confirmed COVID-19 cases increased by 40 percent during the week of January $14^{\text {th }}$, while COVID-19 cases spiked by nearly 20 percent over the same period in nearby Maryland and Virginia (Wines and Bosman 2021). ${ }^{1}$

\footnotetext{
${ }^{1}$ By late January, the U.S. began showing signs that the worst of the late 2020/early 2021 surge had crested (Centers for Disease Control and Prevention 2021).
} 
In the midst of this national surge, there was justifiable public health concern that the January 6 Capitol protest could be a "superspreader" for COVID-19. COVID-19 is spread via droplets from respiratory expulsion such as breathing, speaking, coughing or sneezing (Centers for Disease Control and Prevention 2020a, Fineberg 2020). With widespread distribution of an effective vaccine not yet a reality, public health experts continue to recommend (i) social distancing from non-household members, and (ii) mask-wearing in public, as the most effective strategies to mitigate spread of the novel coronavirus (Centers for Disease Control and Prevention 2020b). According to media reports, very few Capitol protesters wore masks at the event (Ellis 2021), and fewer still socially distanced from non-household members while protesting (Mandavilli 2021). Moreover, the victims of those who broke Federal law by violently entering the Capitol Building often were sometimes forced to choose between their immediate physical safety and their health. Lawmakers, congressional staff members, and law enforcement officials stationed at the Capitol were forced to break social distancing and maskwearing rules as they (i) attempted to flee violent attack by rioters, and (ii) sought cover together in small locked rooms in the Capitol (Cochrane 2021). ${ }^{2}$

In an interview with McClatchy, Dr. Robert Redfield, Director of the Centers for Disease Control and Prevention, predicted that the Capitol Riot would spur a surge of COVID-19. He predicted this surge would not only be caused by increased risk posed to local residents of Washington, D.C., but also for those who have traveled long distances to attend the event and

\footnotetext{
${ }^{2}$ The New York Times reports:
}

“[Normal precautions — already haphazardly enforced — collapsed as pro-Trump supporters stormed the Capitol. Did six feet of distance matter when lawmakers huddled on the ground as a mob tried to break through the door? Or as they tried to rush through tight corridors and into a cramped elevator to a secure space? Or as they sought to comfort a traumatized colleague? On both sides of the Capitol, lawmakers, aides, police officers and reporters who had fled to secure locations have been warned that they might have been exposed to the coronavirus while hiding from the mob.” (Cochrane 2021) 
then returned back to their homes (Redfield 2021). Moreover, leading public health experts argued that the conditions for COVID-19 superspread were nearly ideal (Ellis 2021). ${ }^{3}$

While epidemiologists have nearly uniformly predicted that large gatherings during the COVID-19 pandemic would lead to community-level spread, the actual public health impacts of such events have been far more heterogeneous (Dave et al. 2020a,b,c; Ahammer et al. 2020; Wing et al. 2020). This is, in part, because narrow epidemiological arguments often fail to consider (i) health- or violence-related risk avoidance behaviors of non-participants (Dave et al. 2020a) ${ }^{4}$, (ii) the impact of increased congestion on stay-at-home-behavior, or (iii) the relative risk of counterfactual behaviors in which participants and non-participants would have been engaged in the absence of the gathering (Dave et al. 2020a).

Specifically, public health experts predicted that large social/political rallies from each end of the political spectrum — for example, (i) the Summer 2020 Black Lives Matter protests (Dave et al. 2020a), and (ii) President Trump’s May 2020 Presidential campaign rally in Tulsa, Oklahoma (Dave et al. 2020b) — would cause COVID-19 superspread. However, none of these gatherings did. Empirical analyses of each event produced evidence that local residents increased stay-at-home behavior and reduced foot traffic at restaurants and bars in response to perceived increases in the risks of violence and infectious disease contagion associated with the events. These offsetting risk avoidance behaviors, in conjunction with risk avoidance behaviors

\footnotetext{
${ }^{3}$ Dr. Jonathan Fielding at UCLA told the Washington Post:

"If you wanted to organize an event to maximize the spread of COVID it would be difficult to find one better than the one we witnessed.” (Fielding 2021)

${ }^{4}$ See also, Cronin and Evans (2020) and Gupta et al. 2020) for other examples of health-related risk-avoidance behavior. There is also a wide literature on violence-related risk avoidance (Bennett et al. 2007; Stafford et al. 2007; Roman and Chalfin 2008; Janke, Propper and Shields 2016; Yu and Lippert 2016; Stolzenberg, D’Alessio and Flexon 2019; Fe and Sanfelice 2020).
} 
by gatherers themselves (i.e., temperature taking upon entrance into the Bank of Oklahoma Arena in Tulsa, OK, and mask-wearing among BLM protesters) resulted in no discernible net change in community-level COVID-19 cases.

On the other hand, in the case of the Sturgis Motorcycle Rally in South Dakota, public health experts proved largely correct. In this case, there was evidence of COVID-19 superspread both locally and nationally because (i) there was no offsetting risk avoidance by the local community (Sturgis residents were active participants in the event), and (ii) the event attracted a uniquely large gathering (nearly 500,000 individuals) from all corners of the United States with almost no mitigation. Participants largely did not wear masks, did not socially distance, and were permitted to dine and congregate in indoor venues. These conditions, coupled with the scope of the event, facilitated superspread. Similar evidence of COVID-19 spread has been found with gatherings such as local sporting events (Ahammer et al. 2020; Wing et al. 2020) and in-person primary voting (Cotti et al. forthcoming), for which there is also little evidence of offsetting mitigation.

How does the Capitol Riot compare to these prior events under study? The Capitol Riot is unique in a number of ways. On the one hand, like BLM protests, the Stop the Steal rally and subsequent riot was largely an outdoor event, which would tend to mitigate COVID-19 contagion (Wei and Li 2016). Moreover, as was seen with President Trump’s Tulsa campaign rally — as well as with BLM protests — violence- and health-related risk avoidance associated with the Capitol Riot (which included heavy media coverage of these threats) could lead to (i) increases in stay-at-home behavior by local District of Columbia residents, and (ii) less mixing of local residents with non-household members, which would tend to mute community-level COVID-19 spread. And while media reports suggest that thousands of individuals may have 
attended the January 6 Capitol protests (Doig 2021), the upper bound estimates of the crowd size (approximately 10,000) was nearly 50 times less than the crowd seen at Sturgis and much closer to the crowd size at President Trump’s May 2020 Tulsa Rally, an event that produced little evidence of COVID-19 superspread. Finally, many areas in the District of Columbia near the Capitol were essentially locked down following the Capitol Rally, as local police and the National Guard sought to restore order and protect elected officials from further attack in the weeks leading to President Biden’s inauguration.

On the other hand, some features of the Capitol Riot could lead to a greater risk of spread. First, because some rioters breached the U.S. Capitol Building — leading to crowds gathering indoors — and most protesters did not wear masks, greater COVID-19 spread may be observed with the Riot than was seen for prior events. Second, those who were trapped in the Capitol Building fleeing the "insurrection" were unable to socially distance as they sought refuge from physical violence (Chappell 2021). Third, while the events in Tulsa and in cities that held BLM protests appeared to supplant riskier indoor restaurant and bar-going, during the Capitol Riot in early January, the District of Columbia had closed all restaurants and bars for indoor dining, limiting food service to take-out and outdoor dining only (Office of the Mayor, Washington D.C. 2021). ${ }^{5}$ Entertainment venues and museums were also closed via the Mayor's Order 2020-127. Thus, activities supplanted by the protests may not necessarily have been riskier than the protests themselves. ${ }^{6}$ In summary, whether the Capitol Riot's effects on risk averting

\footnotetext{
${ }^{5}$ Motivated by the surge in COVID-19 cases in D.C. since Thanksgiving, the Order became effective and paused these activities from 10:00 pm December 23 onwards. Initially scheduled to be lifted at on Jan. 15, the moratorium was further extended, in the aftermath of the Capitol Riot, to January 22, two days after the inauguration.

${ }^{6}$ Along the same lines, with regard to nationwide superspread, stay-at-home orders and restrictions on restaurants and bars were far more prevalent in early January throughout the United States than in June during the president's Tulsa campaign rally or during the Sturgis Motorcycle Rally.
} 
behavior and COVID-19 spread were larger or smaller than prior prominent large gatherings remain open questions.

This study is the first to estimate the impact of the January 6 Capitol Riot on mobility and community-level COVID-19 spread. First, using data on anonymized smartphone pings from SafeGraph, Inc. from January 1 through January 11, and an event-study framework, we document that the January 6 events increased total and non-resident cellphone pings by almost 500 percent in the census block groups (CBGs) that contained the Ellipse, the National Mall, and the U.S. Capitol Building. While some of this increase in pings may be explained by the gathering of representatives (Congresspersons and Senators) for the presidential election certification, the size of protesting crowds (numbered in the thousands) vastly dwarfs the number of Federal representatives and staffers, and, as America learned, the number of Capitol police. When we examine the home resident counties from which January 6 protesters came, we find that 2.4 percent of total smartphone "pings" came from Washington, DC residents, 21.9 percent came from bordering Maryland and Virginia, and 75.7 percent came from outside of these judications.

Turning to stay-at-home behavior through January 16, we detect some evidence of risk aversion in response to the Capitol Riot, as local residents increased full-time stay-at-home behavior and percent of time spent at home in the period surrounding and following the Riot. This finding is consistent with violence- or health-related risk averting behavior. Moreover, some of the increase in stay at home behavior appeared to continue beyond the days surrounding the protest, consistent with "lockdown conditions" in many quarters of the District in the period leading up to the inauguration of President Biden. 
Finally, we explore community-level spread of COVID-19 following the Capitol Riot. To explore local spread in Washington, D.C., we use a synthetic control design, creating a “synthetic Washington” using counties with similar urbanicity rates, COVID-19 policy (and testing) environments, and pre-treatment rates of COVID-19 cases and growth rates. We omit from the donor pool those counties with residents whose smartphones were detected at the Capitol Riot on January 6 to avoid spillovers. ${ }^{7}$ Our results provide no evidence of communitylevel COVID-19 spread in Washington, D.C. in the month following the Capitol Riot. This may be explained, in part, by risk averting behavior by local residents and the partial District lockdown.

Turning to counties outside of the District, we use a dose-response “difference-indifferences” approach to explore whether county-level COVID-19 cases spread faster in nonlocalized areas that drew larger shares of residents to the protest relative to counties without attendees represented in Washington, D.C. Our results provide evidence that the Capitol Riot may have contributed to COVID-19 spread in resident counties with relatively higher inflows of Capitol protest participants. For the highest inflow counties, we find that counties with the highest protester inflows experienced a significant increase in the rate of daily cumulative COVID-19 case growth in the month following the protest. We conclude that the Capitol Riot may have led to non-localized community-level COVID-19 spread.

\section{Data}

\subsection{SafeGraph Data}

\footnotetext{
${ }^{7}$ In addition, we omit from the donor pool those counties with a state Capitol to ensure that smaller local January 6 protests in state Capitols did not contaminate our estimates.
} 
Our empirical analyses of the effect of the January $6^{\text {th }}$ Capitol Riot on mobility and COVID-19 spread makes use of two central datasets. The first is the social distancing metrics (SDM) dataset provided by SafeGraph, Inc. These anonymized smartphone data permit us to measure (i) mobility into the areas in which the Capitol protests took place (the Ellipse near the White House, the National Mall, and the U.S. Capitol Building), (ii) the home resident counties of those whose smartphones pinged in the jurisdictions where the protests took place, and (iii) stay-at-home behavior among residents of the District of Columbia.

We begin our analysis using anonymized cellphone data for the period December 26, 2021 through January 16, 2021, a period that envelopes the Capitol protests. ${ }^{8}$ SafeGraph provides data at the census-block-group (CBG)-level from 45 million anonymized cell phones. These data, which have been widely used by economists examining the impacts of stay-at-home orders (Abouk and Heydari 2020; Lasry et al. 2020; Friedson et al. 2020; Dave et al. 2020a,b,c) and large gatherings (Dave et al. 2020d,e,f) on stay-at-home behavior, allow researchers to examine mobility behavior tied to home residences. ${ }^{9}$

In the SafeGraph data, an individual's "home" is defined as the 153-by-153-meter area in which his/her smartphone "pinged" most often between the hours of 6:00PM and 7:00AM during a six-week baseline period. Mobility is measured by documenting when (and for how long) an individual smartphone pings outside of their home residence location. While these data can measure stay-at-home behavior at the extensive (i.e., stay-at-home full-time) and intensive (i.e.,

${ }^{8}$ To obtain SafeGraph data, see: https://www.safegraph.com/covid-19-data-consortium

${ }^{9}$ These data have been used commonly by the Centers for Disease Control and Prevention. 
hours at home or percent of time at home) margins, these data do not permit us to measure other dimensions of social distancing, including social distancing outside of the residence. ${ }^{10}$

Our first purpose in using the SafeGraph data is to explore whether there was an increase in foot traffic in the census block group (CBG) where the Capitol Riot took place, namely the CBG containing the Ellipse, White House, National Mall, and U.S. Capitol Building. This is our definition of the "core protest CBG." In addition, we also explore the "protest CBG cluster," which includes border census block groups to the core protest CBG.

In Figure 1, we show the natural log of total pings (panel a) and non-resident pings (panel b) in the core protest CBG, the protest CBG cluster, and all other CBGs in Washington D.C. during the period from January 1 through January 11. Relative to the period prior to the Riot (January 1 through 4), the total number of pings (panel a) in the "core protest CBG” rose by 73 percent on January 5 (a day when many traveled to the rally) and by about 743 percent on January 6 when the protest took place. Following the $6^{\text {th }}$, we see a sharp decline in smartphone pings. This pattern of smartphone pings is largely driven by non-resident pings (panel b).

A similar pattern is observed when we examine the "protest CBG cluster:” However, in CBGs outside of the protest areas, the increase in smartphone foot traffic is much smaller, though we do note that some protesters undoubtedly traveled in these jurisdictions, accounting for some increases in movement on January 6.

In Figure 2, we present a map of home counties of individuals who visited the core protest CBG on January 4 (panel a), January 6 (panel b), and January 8 (panel c), capturing the periods before, during, and after the Capitol Riot. The heat map reflects the intensity of inflows

\footnotetext{
${ }^{10}$ In addition, we would have difficulty measuring mobility for those who work non-standard night shifts. However, any cross-spatial measurement error should not affect our results because we primarily focus on changes within jurisdictions over time.
} 
into the protests. Following Dave et al. (2020f), we explore five categories of inflows: High, Moderate-High, Moderate, Low, and None. ${ }^{11}$ As illustrated, the events of January 6 (including the protest and certification vote) garnered attendees from all over the United States. While most High inflow counties were in the neighboring jurisdictions (i.e., Prince George’s County, MD; Fairfax County, VA), Harris County, Texas and Wake County, North Carolina also contributed significant attendees. Moreover, in the Moderate-High category, counties in Pennsylvania, California, New York, New Jersey, and Illinois were represented. Attendees at the January 6 events at the Ellipse, National Mall, and Capitol Building were largely not residents of the District of Columbia. Only 2.4 percent of non-resident pings at the core protest CBG were residents of the District. A full 97.6 percent came from outside of D.C., with 75.7 percent coming from outside of D.C., Maryland, and Virginia.

A similar pattern of findings emerges in Figure 3 where we measure inflows to the core protest $\mathrm{CBG}$ by the ratio of total smartphone pings at the protest to total county resident pings overall. As noted in Dave et al. (2020f), this measure is designed to (i) control for county population size (to ensure high inflows do not simply capture large populations), and (ii) account for resident smartphone coverage in the SafeGraph data. In the main, the pattern of high and low inflow counties is relatively similar in Figure 3 as compared to Figure $2 .{ }^{12,13}$

The SafeGraph data also permit us to measure stay-at-home behavior among residents of the District of Columbia. Given insights of prior research on risk-averting behavior in response

\footnotetext{
${ }^{11}$ High absolute inflows correspond to 30 or more pings (13 counties), moderate-high absolute inflows correspond to 15 to 29 pings (44 counties), moderate inflows correspond to 5 to 14 pings (203 counties), low inflows correspond to 1-4 pings (813 counties), and zero inflows correspond to 0 pings (2,059 counties).

${ }^{12}$ High relative inflows correspond to more than 0.0025 relative pings (43 counties), moderate-high relative inflows correspond to [0.0005 to 0.0025 ), relative pings (417 counties), moderate relative inflows correspond to [0.00025 to $0.0005)$ ] relative pings (313 counties), low relative inflows correspond to (0 to 0.00025 ) relative pings (302 counties), and zero relative inflows correspond to 0 pings (2,061 counties).

${ }^{13}$ In Appendix Figure 1, we show a very similar pattern as Figure 2 if we use smartphone pings in the CBG protest cluster.
} 
to violence and health risks (Dave et al. 2020a), we measure stay-at-home behavior of residents of the District of Columbia to capture potential compensatory or avoidance behaviors on the part of the local residents.

Our stay-at-home analysis covers a longer window than our "ping” analysis given that the impacts on stay-at-home behavior in the period leading up to President Biden's inauguration may have been longer-lasting. We use daily data between December 26, 2020 and January 16, 2021 (using two-day rolling averages) on two measures of stay-at-home behavior from the SafeGraph data: (i) Full-Time Stay-at-Home, which measures the mean percent of smartphones that ping exclusively at the home residence for the entire day, and (ii) Percent of Time Spent at Home, which measures the percent of time that the smartphone pings at the home residence. In Washington, D.C., we find that in the days leading up to the protest/certification of President Biden’s victory (January 1 through 4), 39.0 percent of District residents remained at home fulltime. During the period from January 5 (an important arrival day for protesters, as reported in the D.C. media ${ }^{14}$ ) through 7, 42.8 percent of D.C. residents stayed at home full-time. The median percent of time rose by 7.5 percentage-points during the same windows. These pre-post trends are consistent with some risk averting behaviors in response to the Capitol protests.

\subsection{COVID-19 Case Data}

We measure county-level cumulative COVID-19 cases using county-level data collected from state and local health agencies by the New York Times. ${ }^{15}$ COVID-19 cases are analyzed over the period from December 26, 2020 through February 3, 2020, which includes

\footnotetext{
14 See Carless (2021).

15 To obtain county- and state-level COVID-19 case and mortality data, see: https://github.com/nytimes/covid-19$\underline{\text { data }}$
} 
approximately one month of post-protest COVID-19 data. During this time frame, the mean number of cumulative COVID-19 cases per 100,000 population in the District of Columbia was 4,669.9 cases. An over-four-week post-Riot period, while clearly only capturing shorter-run effects, is well beyond the median incubation period for COVID-19 symptoms to emerge (5 days). Thus, during this window, we expect to be able to detect COVID-19 case growth in response to the Capitol Riot for the period under study (Lauer et al. 2020). Indeed, studies on the COVID-19 community-spread effects of the Sturgis Motorcycle Rally (Dave et al. 2020c) and spring break travel (Mangrum and Niekamp 2020) have detected differential growth in COVID19 after two weeks following the end of a large event.

In panel (a) of Figure 4, we show trends in weighted cumulative COVID-19 cases per 100,000 population from December 26, 2020 through February 3, 2021 in High, Moderate-High, Moderate, Low, and No Inflow counties, as measured by absolute inflows. And in panel (b) of Figure 4, we show smoothed trends in daily cumulative COVID-19 case growth across these same inflow counties. ${ }^{16}$ In the pre-Riot period, the average cumulative COVID-19 case rate per 100,000 population was 5332.3 in high absolute inflow counties and the daily cumulative case growth rate was 0.0101 ; this compares to 6943.6 cases per 100,000 population and a daily cumulative COVID-19 case growth rate of 0.0087 in non-inflow counties. ${ }^{17}$ The patterns across these figures provide some descriptive evidence that, in the post-January 6 period, average COVID-19 cumulative case growth was faster in higher inflow as compared to lower or no inflow counties.

\footnotetext{
${ }^{16}$ The data in Figure 5B are "smoothed" using a six-day moving average for ease of optics. We use "raw" individual day COVID-19 case growth for our regression analysis.

${ }^{17}$ In the pre-Riot period, the average cumulative COVID-19 case rate per 100,000 population was 5332.3 in high relative inflow counties and the daily cumulative COVID-19 case growth rate was 0.0095.
} 


\section{Methods}

\subsection{Effect of January 6 Capitol Protest on Non-Resident Travel to Event}

We begin by estimating the effect of the January 6 Capitol Events on total and nonresident cell phone pings in the CBG including the Ellipse, the National Mall, and the U.S. Capitol Building, where the day's protests as well as the election certification took place. We pool 449 CBGs available in the SafeGraph data in Washington, D.C. over a 12-day period and begin by estimating the following simple difference-in-differences specification:

$$
Y_{\mathrm{gt}}=\beta_{0}+\beta_{1} \text { Capitol Protest } \text { gt }+\alpha_{\mathrm{g}}+\tau_{\mathrm{t}}+\varepsilon_{\mathrm{gt}}
$$

where $\mathrm{Y}_{\mathrm{gt}}$ measures the natural $\log$ of (i) the total number of smartphones that pinged in census block group $g$ in the District of Columbia on day $t$, and (ii) the total number of non-resident smartphones that pinged in census block group $g$ in the District of Columbia on day $t, \alpha_{\mathrm{g}}$ is a time-invariant CBG fixed effect and $\tau_{\mathrm{t}}$ is a CBG-invariant day effect that controls for intra-day

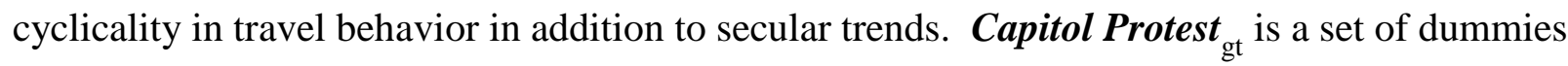
encompassing the post-treatment period, including a single day dummy for January 6th. Moreover, given that the Capitol was cleared rapidly following the riots and resumption of the Congressional session to certify the Electoral College Results, we expect that the lagged effect of the protest to fall to zero in the period following January $6^{\text {th }}$. With regard to statistical inference, because we have a single treated CBG in our sample, we conduct permutation-based tests wherein we randomly assign the treatment to each control CBG and estimate the number of times we would expect a treatment effect as large as the "true" treatment effect (Buchmueller et al 2011; Cunningham and Shah 2018). 
The fact that our sample is restricted to the District of Columbia creates both advantages and disadvantages. For instance, in terms of unobserved heterogeneity bias, we avoid the possibility that unmeasured District-wide policy shocks could contaminate our estimates. In terms of disadvantages, our control CBGs may see spillover effects on mobility to the extent that non-resident travelers to the January 6 events ping across other CBGs as they travel to the U.S. Capitol, biasing our estimates toward zero. To mitigate some of these behavioral effects, we explore the robustness of our findings to omitting "border" CBGs from the analysis sample. We also explore the sensitivity of our estimates to defining the treatment jurisdictions as the CBG protest cluster.

In addition, to guard against estimates being biased by unmeasured CBG-specific time trends, we augment the right-hand side variables to include CBG-specific time trends:

$$
Y_{\mathrm{gt}}=\beta_{0}+\beta_{1} \text { Capitol Protest } \text { gt }+\alpha_{\mathrm{g}}+\tau_{\mathrm{t}}+\alpha_{\mathrm{g}} *_{\mathrm{t}}+\varepsilon_{\mathrm{gt}}
$$

where $\alpha_{\mathrm{g}}{ }_{\mathrm{t}}$ is a CBG-specific linear time trend.

Finally, we conduct event study analyses to explore whether mobility patterns were common in the period leading up to the January 6 Capitol events. A pattern of common pretrends provides at least descriptive evidence in support of the common trends assumption.

\subsection{Effect of Capitol Protest on Stay-at-Home Behavior \& COVID-19}

To examine the impact of the January 6 Capitol events on stay-at-home behavior and COVID-19 cases among the District of Columbia’s resident population, we undertake a synthetic control approach (Abadie et al. 2010). Our local COVID-19 spread analysis focuses on the 
District of Columbia, where the event took place and the location of the largest number of smartphone pings in the SafeGraph data, and covers the period from December 26, 2020 to January 16, 2021. ${ }^{18}$

To conduct our synthetic control analysis, it is necessary to choose a donor pool and “match" observables to generate our "synthetic Washington D.C.” The District of Columbia includes approximately 700,000 residents within the jurisdiction (U.S. Census Bureau 2019) and according to the U.S. Census has an urbanicity rate of 100 percent (U.S. Census Bureau 2010). Our donor pool is comprised of similar counties that meet the following criteria:

- counties are not located in Virginia or Maryland, where spillovers are most likely given the distribution of smartphone pings shown in Figure 2;

- counties have no residents whose smartphone pings in the core treatment CBG in Washington, D.C. on January 6, 2021;

- the county urbanicity rate was at least 80 percent; and

- counties do not include a state capitol, where local protests may have taken place on January 6 (sensitivity checks)

These restrictions help to select on factors that may be important to COVID-19 spread (Friedson et al. 2020; Dave et al. 2020b,c). ${ }^{19}$ We also explored the sensitivity of results to alternate urbanicity cutoffs as well as the use of a measure of county population density, but our findings were not sensitive to these choices.

In addition to the construction of our donor pool, to further ensure that "synthetic D.C." is

\footnotetext{
${ }^{18}$ This method has been used by several recent studies to investigate how shelter-in-place orders (Friedson et al. 2020; Dave et al. 2020d,e) and large gatherings (Dave et al. 2020a,b,c) have affected stay-at-home behavior, foot traffic, and community-level COVID-19 growth.

${ }^{19}$ The imposition of each of these restrictions yields 105 donor counties. The inclusion of counties that include state Capitols yields a donor pool of 108 counties.
} 
a credible counterfactual to the District of Columbia, our primary estimation strategy matches on outcomes (stay-at-home behaviors, COVID-19 cases per capita) on each day prior to the January 6 event. We also explore the sensitivity of our synthetic control estimates to use of an alternative matching strategy of matching on five days of pre-treatment COVID-19 case rates ${ }^{20}$ and adding observable matching characteristics that could affect COVID-19 case growth (or stay-at-home behavior): the county urbanicity rate, county weighted population density, the number of days a mask-wearing policy was in effect, whether the state had a stay-at-home advisory ${ }^{21}$, whether the state had imposed restrictions on indoor dining/drinking at restaurants and bars, and in the case of COVID-19 cases, a COVID-19 testing rate trend. ${ }^{22}$ Our synthetic control estimate is then calculated as the difference in average post-treatment COVID-19 cases between the treated jurisdiction and its synthetic control. ${ }^{23}$

\subsection{Estimating Non-Localized "Superspread” from Capitol Riot}

To examine the nationwide spread effects of the January 6 Capitol Riot, we pool a panel of 3,137 counties and 40 days from all U.S. states except the District of Columbia (which is analyzed in the above local spread analysis) and estimate the following dose-response differencein-differences model:

\footnotetext{
${ }^{20}$ For stay at home behavior, these days are December 27, December 29, December 31, January 2, and January 4. We allow January 5 (a travel day to attend the event) for stay at home behavior to diverge. For our COVID-19 case analysis, these days are December 28, December 30, January 1, January 3, and January 5.

${ }^{21}$ Over the sample period, California lifted their stay-at-home advisory and curfew policy. However, given that there were relatively few days of post-treatment data over our analysis period, we treat this policy as time-invariant over our sample window for the synthetic control analysis. However, our results do not qualitatively change with an alternate coding. Our dose-response analysis allows this policy to vary daily.

22 The days on which the testing rate is matched includes December 31, January 5, January 15, and January 30.

${ }^{23}$ For instance, the unobserved counterfactual for COVID-19 case rate for the District of Columbia is given by $\sum_{j} w_{j} * \operatorname{COVI} D_{j t}$, where $w_{j}$ is the weight allocated to donor county $j$ on day $t$. The estimated weights are selected for all pre-treatment days to minimize the absolute difference between $\operatorname{COVID}_{i=D C, t}$ and $\sum_{j} w_{j} * \operatorname{COVID}_{j t}$. The treatment effect $\alpha_{t}$ is assessed as $\alpha_{t}=\operatorname{COVID}_{i=D C, t}-\sum_{j} w_{j} * \operatorname{COVID} D_{j t}$ for $t \epsilon\{$ January 6, February 3\}, which is used to construct the average treatment effect over the post-treatment window.
} 
COVID_Growth $\mathrm{cst}_{-}=\alpha_{0}+$ Travelers $_{\mathrm{c}} * \operatorname{Post}_{\text {Protest }_{\mathrm{t}}} * \boldsymbol{\alpha}_{\mathbf{1}}+\mathbf{X}_{\mathrm{st}} * \boldsymbol{\alpha}_{2}+\gamma_{\mathrm{c}}+\delta_{\mathrm{t}}+\gamma_{\mathrm{c}} * \mathrm{t}+\varepsilon_{\mathrm{cst}}$

where COVID_Growth cst $_{\text {is }}$ the daily growth in cumulative COVID-19 cases (following

Courtemanche et al. 2020) ${ }^{24}$, Travelers $_{\mathrm{c}}$ is a set of four indicators of intensity of inflows to the core treatment CBGs in Washington D.C. on January $6^{\text {th }}$ from resident county $c$ relative to counties that had zero inflow (reference). These categories correspond to the inflow categories

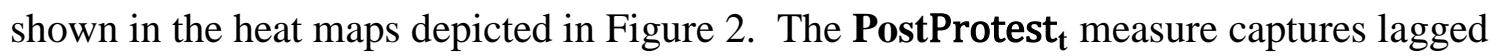
windows of the post-treatment period beginning on January 6 and ending February 3, nearly one month following the Capitol Riot. ${ }^{25,26}$ The coefficient $\boldsymbol{\alpha}_{1}$ captures the differential impact of the U.S. Capitol protest on COVID-19 cumulative COVID-19 case growth in counties in the four inflow groups described above relative to counties without any inflows to the protest on January 6.

Our controls are as follows: $\mathbf{X}_{\mathbf{s t}}$ includes the COVID-19 testing rate per 100,000 population, whether the state has a shelter-in-place advisory in effect, whether the state has a mask mandate, and whether the state allows opening of indoor dining for restaurants and bars. Finally, $\gamma_{\mathrm{c}}$ is a time-invariant county effect, $\tau_{\mathrm{t}}$ are county-invariant day effects, and $\gamma_{\mathrm{c}}{ }^{*} \mathrm{t}$ is a county-specific linear time trend. The latter helps to control for differential growth trends of

\footnotetext{
${ }^{24}$ In approximately 1 percent of county-days, cumulative COVID-19 cases are reported as falling, likely due to reclassification of cases across time and jurisdictions. In unreported robustness checks, we find that are main findings are qualitatively unchanged if we recode these declines in cumulative cases as missing or use the methodology outlined by Courtemanche et al. (2020) to recode declining county-days to 0 (along with adjacent days of the decline in some cases).

${ }^{25}$ This model also includes controls for leads for the Capitol Riot of up to 10 days prior to the event, mirroring the event studies shown in Figures 8 and 9. All regressions are weighted by the county population (though we also present unweighted estimates for comparison) and standard errors are clustered at the state level.

${ }^{26}$ As noted above, this post-treatment window captures a period well past the median incubation period (5 days) for COVID-19, and surpasses the point where 99 percent of individuals who are infected would have started showing symptoms (Lauer et al. 2020).
} 
COVID-19 across counties. ${ }^{27}$ Our primary strategy of assessing the common trends assumption is, again, to conduct event study analysis across each of our inflow groups relative to no inflow counties. ${ }^{28}$

\section{Results}

Our main findings appear in Tables 1 through Table 5 and Figures 5 through 9. Supplemental results are shown in the appendix.

\subsection{SafeGraph Results on Mobility}

We begin by exploring the impact of the January 6 Capitol Riot on mobility. Table 1 presents estimates of $\beta_{1}$ from equations (1) and (2). We find that relative to non-protest CBGs in the District of Columbia, the total number of pings increased in the core protest CBG by 478 percent on January 6 (Panel I, column 1 ). ${ }^{29}$ Following the $6^{\text {th }}$, the number of pings in the protest CBG fell to match non-protest CBG foot traffic. This result is consistent with police dispersal of protest crowds and the conclusion of Congressional business. Our findings are largely unchanged when we include controls for CBG-specific linear time trends (Panel I, column 2).

In Panel II, we explore whether the effects we observe in Panel I are muted by the inclusion of border CBGs to the core treatment CBG in the control group. Consistent with this hypothesis, we find slightly larger increases in the total number of smartphone pings associated with the January 6 events (Panel II, columns 1 and 2).

\footnotetext{
${ }^{27}$ When we estimated dose response models that excluded county-specific linear time trends, the pattern of results was quite similar to those we report.

${ }^{28}$ Our main tables and figures present results from weighted dose-response difference-in-differences estimates, which are weighted.

${ }^{29}$ The effect is $(\mathrm{e} 1.755-1)=4.78=478 \%$.
} 
We find that January 6-induced increases in cell phone pings at the Ellipse, National Mall, and Capitol were largely driven by non-residents of the District (columns 3 and 4). Specifically, we find that the January 6 Capitol Riots are associated with a 402 to 452 percent increase in non-resident smartphone pings. Together, the results in Table 1 are consistent with a large protest event at the U.S. Capitol. ${ }^{30}$

Figure 5 shows the event study analyses associated with the main estimates in Table 1. We find that in the period prior to the January 6 Capitol Riots, total (panel a) and non-resident (panel b) smartphone pings trended similarly in the treatment and control CBGs. However, on January 6, the day of the election certification and protests, foot traffic in the treatment CBGs rose by almost 500 percent relative to the control CBGs before falling back to statistical equivalence in the days following the protest. A similar pattern of results is detected when we omit CBGs that border the core treatment CBGs from the analysis sample (see panels c and d). These results are consistent with a causal interpretation of the estimates shown in Table 1.

In Figure 6 and Table 2, we explore whether there was local risk averting behavior in response to the January 6 riot. Specifically, we examine the impact of the January 6 Capitol Riot on stay-at-home behavior by local residents of the District of Columbia. Panel (a) shows synthetic control estimates on full-time stay-at-home behavior when we generate "synthetic D.C.” by matching on each pre-treatment day of the outcome under study. Our results show that D.C. and synthetic D.C. track each other nearly identically in the pre-treatment period. However, beginning on the day on which many non-resident protesters arrived in the city (January 5) and continuing/peaking on the day of the protest (January 6), we see that full-time stay-at-home behavior sharply rises in the District of Columbia relative to the synthetic control,

\footnotetext{
${ }^{30}$ In Appendix Table 1, we show estimated effects when we include border CBGs as part of the treatment group.
} 
which is comprised of San Francisco County, CA (53.4 percent), Denver County, CO (19.4 percent), Val Verde County, TX (19.4 percent), DeKalb County, IL (5 percent), and Sarpy County, NE (2.8 percent). The largest divergence in full-time stay-at-home behavior is seen between January 5 through 7 before converging again. ${ }^{31}$

When we examine median percent of time at home (panel b), we also see a relative increase in stay-at-home behavior among local District residents, though this increase appears to be more "long-term,” perhaps suggesting that the intensive margin of stay-at-home behavior is affected by the Riot and its aftermath. Indeed Washington, D.C. appeared to enter "virtual lockdown” in the turbulent period leading to President Biden and Vice President Kamala Harris’s inauguration on January $20^{\text {th }}$ (Baldwin, McNamara, and Linton 2021) and the moratorium on indoor dining and other restrictions as per the Mayor's Order were extended to two days following the inauguration.

In panels (c) and (d) of Figure 6, we repeat the exercise with an alternate matching procedure, matching on the pre-treatment outcome on every other pre-treatment day, beginning on December 26 and adding matching controls for: the county urbanicity rate, county population density, the average state COVID-19 testing trend, and the number of days the state had a mask mandate, a stay-at-home order, and banned indoor dining/drinking at restaurants and bars. Our synthetic control results in panels (c) and (d) produce a pattern of results similar to panels (a) through (b), and consistent with the hypothesis of risk averting behavior in response to the Riot.

Table 2 shows synthetic control estimates of the effect of the Capitol Riot on stay-athome behavior. Columns (1) and (3) correspond to the panels shown in Figure 6. Column (2)

\footnotetext{
${ }^{31}$ We note that in this model, Denver, CO, which had a state Capitol protest on January 6, is a minority "matching county" for Washington, D.C. This could bias estimated stay-at-home behavior toward zero if there were riskaverting behavior in Denver as well. In a subsequent specification shown in Table 2 that excluded Denver, Colorado from the donor pool, we detect a qualitatively similar pattern of results.
} 
shows results from a model that matches on the outcome in every other pre-treatment day plus the county urbanicity rate and population density. And in column (4), we drop counties that included a state Capitol, which may have had a local protest scheduled at a State House (Cremen 2021; Reuters 2021). Across these specifications, we show that the Capitol Riots are associated with a 3.6 to 4.5 percentage-point increase (10.1 to 12.5 percent increase relative to the baseline mean) in full-time stay-at-home behavior during the January 5 to 6 period. Standard permutation-based p-values do not allow us to definitively claim that this difference is statistically distinguishable from zero at conventional levels though this pattern is suggestive.

Turning to median percent of time at home (columns 5-8), we find consistent evidence that the Capitol Riot led to longer-run risk averting behavior. We find that the Riot was associated with a 10 to 12 percentage-point increase (13 to 17 percent) in median percent of time at home among D.C. residents during the January 5 to 6 period (p-values $=.02$ to .07 ). Moreover, there is evidence that the effect on median percent time at home persists and increases over the longer-run as well (January 7 and later). This is consistent with the "virtual lockdown” in Washington, D.C. following the Capitol Riot in the period leading up to President Biden’s inauguration.

Together, the findings in Figure 6 and Table 2 are consistent with the hypothesis of riskaverting increases in stay-at-home behavior in D.C. This result may suggest that any community-level spread of COVID-19 in the District may be muted. We explore this below.

\subsection{Local COVID-19 Spread in the District of Columbia}

In Figure 7 and in Table 3, we explore whether the Capitol Riots contributed to local community spread of COVID-19. Panel (a) of Figure 7 shows synthetic control estimates for the 
model where we match on all pre-treatment days of cumulative COVID-19 cases while panel (b) shows estimates where we match on every other pre-treatment day beginning on December 26 as well as on other predictors of community spread described above. Across both sets of figures, we find very little evidence that the Capitol Riot led to significant COVID-19 spread in the District up to approximately one month following the Riot.

Table 3 presents the synthetic control estimates of the effect of the Capitol Riots on cumulative COVID-19 cases (columns 1 through 4) as well as the natural log of cumulative COVID-19 cases (columns 5 through 8). Panel I shows a single estimate over the full posttreatment period, while Panel II divides the post-treatment period into windows that capture the early (January 6-12) and later (January 13 to 19) 14-day-incubation period and the postincubation period (January $20^{\text {th }}$ and later). Across specifications focusing on COVID-19 case levels (columns 1 through 4), we generally find that over the full post-treatment period, the Capitol Riot was associated with a statistically insignificant and economically small decline in COVID-19 cases per 1,000 residents in the District during the full post-treatment window (Panel I). These estimated effects are not statistically distinguishable from zero using permutationbased p-values generated from placebo tests. In columns (5) through (8) we use the natural log of COVID-19 cases as the outcome measure. Note that by matching on pre-Riot days of the log COVID-19 cases, we assure that "synthetic D.C." has the same rate of pre-Riot COVID-19 case growth as the District. Our pattern of findings is very similar.

In Panel II, we explore the longer-run impact on community-level COVID-19 spread to be sure that our findings do not mask important divergence on COVID-19 case growth in the post-14-day incubation period. We continue to find little evidence that the Riot increased COVID-19 spread in the District of Columbia in the near month-long period following the Riot. 


\subsection{Non-Localized Spread of COVID-19 Cases}

Finally, we assess the degree to which the Capitol Riots of January 6 contributed to nonlocalized COVID-19 spread in counties with relatively higher inflows of attendees to the Capitol protests. For this purpose, we exclude the District of Columbia from the analysis sample, as this jurisdiction was examined in our local spread analysis in Section 4.2 above. We use our doseresponse difference-in-differences model (equation 3) to assess whether counties with relatively higher numbers of residents attending Capitol events saw greater COVID-19 spread following the event, when many protesters returned home. Figure 8 and Table 4 present the results of this exercise.

Figure 8 presents event-study analyses of the effect of absolute inflows into the Capitol Events of January 6 on cumulative daily COVID-19 case growth in attendees' resident counties. Note that the estimates show COVID-19 effects relative to counties with no inflows to the Capitol on January 6. Our event study results show little evidence of differential pre-treatment county-level COVID-19 case growth trends, consistent with the hypothesis that the treatment and control counties were quite similar in the days leading up to the Capitol Rally. Moreover, we find that across the lowest inflow groups, there is very little evidence of more rapid COVID-19 case growth, including in the period following COVID-19's full 14-day incubation period and even up to three or more weeks following the Rally. However, in the highest inflow counties, we

find that the Capitol Riot is associated with a significant increase in daily cumulative COVID-19 case growth. The effects begin in the period including the $50^{\text {th }}$ to $75^{\text {th }}$ percentile of the incubation period for COVID-19 and continue through approximately one month following the Riot. 
Table 4 presents the lagged effects of absolute Capitol Riot inflows on COVID-19 case growth. Column (1) includes the full set of fixed effects and county linear time trends and column (2) adds the observable control variables mentioned above. Across these specifications, we find consistent evidence that COVID-19 cases grew faster in higher inflow counties relative to counties that did not contribute any protest participants. In our most saturated specification (column 2), we find that the Riot was associated with an approximate 0.4 to one percentage point increase in daily COVID-19 case growth. ${ }^{32,33}$ Accounting for the uncertainty around these estimates implied by our estimated standard errors, our lower bound estimates from the 95 percent confidence intervals would suggest a 0.15 to 0.24 percentage point increase. In column (3), we omit counties from the sample that include state Capitols where there may have been, albeit smaller, protests. Our results show a slightly larger increase in daily cumulative COVID19 case growth, reaching just over a percentage-point in the longest lag window (21 or more days following the Riot). ${ }^{34}$

To ensure that the estimates shown in columns (1) through (3) of Table 4 were not driven by high population counties or by idiosyncratic SafeGraph coverage differences across counties, we next use our relative inflow measure that normalizes absolute inflows by the total resident pings in the county. Figure 9 shows event-study analyses of the effects of relative inflows into the U.S. Capitol on the natural log of COVID-19 cases. Consistent with our absolute inflow measure, we find no evidence that COVID-19 grew faster in lower inflow counties relative to

\footnotetext{
${ }^{32}$ For high absolute inflow counties, we estimate a pre-Riot cumulative COVID-19 daily case growth mean of 0.0101. For high relative inflow counties, we estimate a pre-Riot cumulative COVID-19 case growth rate mean of 0.0095

${ }^{33}$ In Appendix Table 2, we replicate columns (1) and (2) of Table 4 using the inverse hyperbolic sine transformation of daily COVID-19 cases. While much less precisely estimated, the results are qualitatively similar to those shown in Table 4.

${ }^{34}$ In Appendix Table 3, we add controls for census division-by-day fixed effects to control for common regionspecific shocks that may be correlated with the timing of the Capitol Riot and with COVID-19 growth. The results are qualitatively similar to those reported in Table 4.
} 
counties without inflows. However, in higher inflow counties, we find consistent evidence that the Capitol Riot was associated with an increase in daily COVID-19 case growth, beginning in the period after the median incubation period of COVID-19 and continuing through approximately one month following the rally.

In columns (4) through (6) of Table 4, we show dose-response estimates using the relative inflow measure. We find that in high inflow counties, the Riot was associated with a 0.5 to 1.1 percentage point increase in COVID-19 case growth. These findings, consistent with our absolute inflow results, suggest that the January 6 Capitol events contributed to non-localized COVID-19 spread and generated potentially important public health costs. ${ }^{35,36}$

\subsection{Mitigating Policies}

Could home county mitigating policies have blunted non-localized COVID-19 spread from the Capitol Riot? In Table 5, we explore whether the effects of the Capitol Riot on nationwide spread differed by whether, on January $6^{\text {th }}$, the state had imposed restrictions on indoor dining at restaurants or bars (capacity constraints or outright bans). There is evidence that indoor dining/drinking among non-household members may play an important role in the spread of COVID-19 (Courtemanche et al. 2020; Dave et al. 2020c,f). In the context of other large gatherings involving participants who have traveled long distances, community-level spread of COVID-19 when protesters return home appears to be muted by mitigation policies such as restrictions on indoor dining at restaurants (Dave et al. 2020c). Thus, in Table 5, we interact

\footnotetext{
${ }^{35}$ The estimates shown in Table 4 are weighted using the county population. In Appendix Table 4, we show results from unweighted regressions. The pattern of results is qualitatively similar.

${ }^{36}$ In Appendix Tables 5A and 5B, we explore the impact of the Capitol Riot on COVID-19-related deaths. Consistent with out findings on COVID-19 cases in the District of Columbia, we find no evidence that the Riot contributed to additional local COVID-19 deaths. However, while imprecisely estimated, our dose response results suggest that the Riot may have contributed to increased non-localized COVID-19-related mortality.
} 
Travelers $c$ with an indicator for whether the state restricted indoor dining or drinking at restaurants or bars and required mask wearing in public places. For our absolute inflow measure, the strongest mitigation policy for which we have sufficient variation for identification in our highest inflow category is a state mandate for partial (or greater) restrictions on indoor dining at restaurants and drinking at bars. For our relative inflow measure, we can construct a stricter mitigation policy: full bans on indoor dining/drinking at bars and some restrictions or a full ban on dining at restaurants.

The results in Table 5 provide evidence that existing mitigation policies in the home state of Capitol protesters may have played an important role in reducing spread of COVID-19 following the Riot. This result is especially stark in the case of our strongest mitigation policy using our relative ping measure. In the highest inflow category, we find that that the Riot was associated with a 0.7 to 1.4 percentage point increase in county-level COVID-19 case growth when the rally attendee's home state did not ban indoor dining at restaurants and drinking at bars. ${ }^{37}$ However, when such activities were banned, the Riot had a small and statistically insignificant effect on COVID-19 spread. While we are cautious in interpretation given that the policy variation we exploit is cross-sectional, these findings suggest that there is scope for public policy to mitigate community-level spread of COVID-19. ${ }^{38}$

\section{Conclusions}

On January 6, 2021, one of the most dramatic political events in modern American history took place when supporters of outgoing President Donald J. Trump stormed the U.S.

\footnotetext{
${ }^{37}$ Accounting for the uncertainty surrounding the estimates, the lower bounds of the 95 percent confidence intervals are suggestive of an increase of about 0.3 to 0.6 percentage points.

${ }^{38}$ In unreported results, we explore whether state mask mandates mitigated the COVID-19-spread effects of the Capitol Riot. We find no evidence that such policies were associated with slower case growth in high inflow counties.
} 
Capitol Building to protest the certification of the elections of President Joseph R. Biden and Vice President Kamala Harris. Termed an "insurrection” by the U.S. Congress, this event challenged the nation's tradition of a peaceful transition of political power across executives. But in addition to the threats posed to the nation's democracy, some public health experts, including the Director of the Centers for Disease Control and Prevention, argued that the Capitol Riot could cause a resurgence of COVID-19 in Washington, D.C. and nationwide. This study is the first to explore this question.

First, using data from SafeGraph, we document that non-resident smartphone presence at the Ellipse, National Mall, and U.S. Capitol Building rose substantially on January 6, 2021. Moreover, we find evidence that local residents of Washington, D.C. engaged in risk avoidance behavior in response to this event. Stay-at-home behavior at the extensive margin (full-time stay at home behavior) and the intensive margin (percent of time spent at home) rose in response to the event. This result is consistent with risk-averting behavior in response to, perhaps, risks of violence and COVID-19 spread. Risk aversion may also rise in response to congestion effects as, during and after the protests, many streets were closed, and traffic rerouted as the Capitol police regained control of the city and the National Guard was called out. Moreover, some of the stay-at-home behavior induced by the Riot appeared to continue long past the event itself, owed to the "virtual lockdown” of Washington, D.C. in the period leading up to President Biden’s inauguration.

Perhaps in part because of this increase in social distancing, evidence from our synthetic control models provide no evidence of local COVID-19 spread in Washington, D.C. in the month following the event. However, when we explore whether there were non-localized spillover effects of the Capitol Riot, our dose response models suggest that counties that 
contributed higher inflows to Washington, D.C. on January 6 saw larger increases in daily COVID-19 case growth. This result is consistent with Center for Disease Control and Prevention warning that large gatherings of non-household members who do not engage in mitigation generates the conditions for substantial risk for community-level COVID-19 spread.

Descriptive evidence suggests that there may be an important role for policy in blunting the adverse public health consequences of risky large gatherings. Restrictions in Washington, D.C. and in counties that contributed relatively higher inflows to the Capitol may have helped curb COVID-19 spread following the Riot, moderating interactions outdoors and risky activities (for instance, going to restaurants and bars) once protesters traveled back to their resident communities. Moreover, averting behaviors, particularly in the District of Columbia, which may include increases in stay-at-home behavior as well as enhanced mask-wearing may have helped cap COVID-19 growth.

Our analysis, of course, only captures short-run estimates of the effect of the Capitol Riot on community-level COVID-19 spread. While our post-treatment window captures a period beyond the incubation window of COVID-19, additional weeks of data will provide a fuller picture of the public health impacts of the event. Importantly, we note that our COVID-19 data do not allow us to specifically measure disease spread among those protesting or among those working in the Capitol Building on the day of the Riot. Precise and complete contact tracing would be required to document person-to-person spread among those who had contact with rioters. Our estimates should, therefore, be interpreted as the event's net effect on communitylevel COVID-19 cases. Distributional effects may, of course, be important as well. 


\section{References}

Abadie, A., Diamond, A. and Hainmueller, J. (2010). "Synthetic Control Methods for Comparative Case Studies: Estimating the Effect of California's Tobacco Control Program.” Journal of the American Statistical Association 105 (490): 493-505.

Abouk, R, and Heydari, B. (2020). "The Immediate Effect of COVID-19 Policies on Social Distancing Behavior in the United States.” Retrieved from SSRN: https://ssrn.com/abstract=3571421

Adeline, Stephanie, Connie Hanzhang Jin, Alyson Hurt, Thomas Wilburn, Daniel Wood, and Ruth Talbot. 2021. Coronavirus Is Surging: How Severe Is Your State's Outbreak? January 14, 2021. National Public Radio. https://www.npr.org/sections/healthshots/2020/09/01/816707182/map-tracking-the-spread-of-the-coronavirus-in-the-u-s

Ahammer, Alexander, Martin Halla \& Mario Lackner, 2020. "Mass Gatherings Contributed to Early COVID-19 Mortality: Evidence from US Sports," Economics working papers 2020-13, Department of Economics, Johannes Kepler University Linz, Austria.

Baldwin, Sarah L., Audrey McNamara, and Caroline Linton. Washington, D.C., locks down as inauguration events kick off. January 17, 2021. CBS News.

https://www.cbsnews.com/live-updates/joe-biden-inauguration-washington-dc-lockdown/

Balsamo, Michael. 2021. Discovery of pipe bombs in DC obscured by riot at Capitol. January 11, 2021. The Associated Press. https://apnews.com/article/donald-trump-joe-bideninaugurations-capitol-siege-8828a6a920198d0ea1ee0c73a49d8847

Bennett, G.G., McNeill, L.H., Wolin, K.Y., Duncan, D.T., Puleo, E. and Emmons, K.M., 2007. Safe to walk? Neighborhood safety and physical activity among public housing residents. PLoS medicine, 4(10).

Booker, Brakkton. 2021. About 20,000 National Guard Members to Deploy for Inauguration, Officials Say. January 13, 2021. National Public Radio. https://www.npr.org/sections/insurrection-at-the-capitol/2021/01/13/956458463/20-000national-guardsmen-will-be-deployed-for-inauguration-d-c-official-says

Buchmueller, T. C., DiNardo, J., \& Valletta, R. G. 2011. The effect of an employer health insurance mandate on health insurance coverage and the demand for labor: Evidence from Hawaii. American Economic Journal: Economic Policy, 3(4), 25-51.

Carless, Will. 2021. Nation's capital braces for violence as extremist groups converge to protest Trump’s election loss. January 4, 2021. USA Today. https://www.usatoday.com/story/news/nation/2021/01/04/january-6-dc-protests-againstelection-certification-could-violent/4132441001/ 
Chappell, Bill. 2021. 3rd Member of Congress Tests Positive for Coronavirus, Blames Capitol Attack Lockdown. January 12, 2021. National Public Radio. https://www.npr.org/sections/insurrection-at-the-capitol/2021/01/12/955976431/repjayapal-blames-insurrection-lockdown-after-testing-positive-for-covid-19

Cochrane, Emily. 2021. Did Mixing a Riot with a Pandemic Yield a Superspreader Event? January 11, 2021. The New York Times. https:/www.nytimes.com/2021/01/11/us/politics/us-capitol-super-spreadercoronavirus.html

Cotti, Chad D., Bryan Engelhardt, Joshua Foster, Erik T. Nesson, Paul S. Niekamp. Forthcoming. "The Relationship between In-Person Voting and COVID-19: Evidence from the Wisconsin Primary,” Contemporary Economic Policy.

Courtemanche, C., Garuccio, J., Le, A., Pinkston, J., Yelowitz, A., 2020. Strong Social Distancing Measures in The United States Reduced The COVID-19 Growth Rate. Health Affairs 10.1377/hlthaff.2020.00608. https://doi.org/10.1377/hlthaff.2020.00608

Cremen, Alanea. 2021. 11 arrested for having pepper spray at Capitol demonstrations. January 6, 2021. ABC 10 News, Sacramento. https://www.abc10.com/article/news/local/sacramento/hundreds-gather-at-sacramentocapitol-to-protest-2020-election/103-d2e330bd-1268-404f-8edc-bc97bef71629

Cronin, C.J., and Evans, W.N. 2020. Private Precaution and Public Restrictions: What Drives Social Distancing and Industry Foot Traffic in the COVID-19 Era? Working Paper No. 27531. Working paper Series. National Bureau of Economic Research.

Cunningham, S. and Shah, M. 2018. Decriminalizing Indoor Prostitution: Implications for Sexual Violence and Public Health. The Review of Economic Studies, 85(3), pp.16831715.

Dave, D.M., Friedson, A.I., Matsuzawa, K., Sabia, J.J. and Safford, S. 2020a. Black Lives Matter Protests, Social Distancing, and COVID-19. Working Paper No. 27408. Working Paper Series. National Bureau of Economic Research.

Dave, D.M., Friedson, A.I., Matsuzawa, K., McNichols, D., Redpath, C. and Sabia, J.J. 2020b. Risk Aversion, Offsetting Community Effects and COVID-19: Evidence from an Indoor Political Rally. Working Paper No. 27552. Working Paper Series. National Bureau of Economic Research.

Dave, D.M., McNichols, D. and Sabia, J.J. 2020c. The Contagion Externality of a Suprespreading Event: The Sturgis Motorcycle Rally and COVID-19. Southern Economic Journal, Forthcoming.

Dave, D.M., Friedson, A.I., Matsuzawa, K., McNichols, D., Sabia, J.J., 2020d. Did the Wisconsin Supreme Court Restart a COVID-19 Epidemic? Evidence from a Natural 
Experiment (Working Paper No. 27322). National Bureau of Economic Research. https://doi.org/10.3386/w27322

Dave, D.M., Friedson, A.I., Matsuzawa, K., Sabia, J.J., 2020e. When Do Shelter-in-Place Orders Fight COVID-19 Best? Policy Heterogeneity Across States and Adoption Time. Forthcoming, Economic Inquiry.

Dave, D.M., Friedson, A.I., Matsuzawa, K., Sabia, J.J., Safford, S., 2020f. Were Urban Cowboys Enough to Control COVID-19? Local Shelter-in-Place Orders and Coronavirus Case Growth. Forthcoming, Journal of Urban Economics.

Doig, Steve. 2021. It is difficult, if not impossible, to estimate the size of the crowd that stormed Capitol Hill. January 8, 2021. The Conversation. https://theconversation.com/it-isdifficult-if-not-impossible-to-estimate-the-size-of-the-crowd-that-stormed-capitol-hill152889

Ellis, Ralph. 2021. Capitol Riot Likely a Superspreader Event. January 11, 2021. WebMD. https://www.webmd.com/lung/news/20210110/capitol-riot-likely-a-superspreader-event

Fandos, Nicholas and Emily Chochrane. 2021. After a day of chaos, Congress certifies Joe Biden’s election victory. January 7, 2021. The New York Times. https://www.nytimes.com/live/2021/01/06/us/electoral-vote

Fe, Hao, and Viviane Sanfelice. 2020. How Bad is Crime for Business? Evidence from Consumer Behavior. Center for Health Economics and Policy Studies Working Paper No. 2021101.

Friedson, Andrew I., Drew McNichols, Joseph J. Sabia, and Dhaval Dave. 2020. "Shelter-inPlace Orders and Public Health: Evidence from California During the COVID-19 Pandemic.” Forthcoming, Journal of Policy Analysis and Management.

Gupta, S., Nguyen, T.D., Rojas, F.L., Raman, S., Lee, B., Bento, A., Simon, K.I. and Wing, C. 2020. Tracking Public and Private Responses to the COVID-19 Epidemic: Evidence from State and Local Government Actions. NBER Working Paper No. 27027.

Hsu, Spencer S., Tom Jackman, and Devlin Barrett. 2021. Self-styled militia members planned on storming the U.S. Capitol days in advance of Jan. 6 attack, court documents say. January 19, 2021. The Washington Post. https://www.washingtonpost.com/local/legalissues/conspiracy-oath-keeper-arrest-capitol-riot/2021/01/19/fb84877a-5a4f-11eb-8bcf3877871c819d_story.html

Janke, K., Propper, C. and Shields, M.A., 2016. “Assaults, murders and walkers: The impact of violent crime on physical activity.” Journal of Health Economics, 47, pp.34-49.

Lasry, A., Kidder, D., Hast, M., Poovey, J., Sunshine, G., Zviedrite, N., Ahmed, F. and Ethier, K.A., (2020). "Timing of Community Mitigation And Changes in Reported COVID-19 
And Community Mobility-Four US metropolitan Areas.” Morbidity and Mortality Weekly Report, 69(15): 451-457

Lauer, Stephen A., Kyra H. Grantz, Qifang Bi, Forrest K. Jones, Qulu Zheng, Hannah R. Meredith, Andrew S. Azman, Nicholas G. Reich, and Justin Lessler. "The Incubation Period of Coronavirus Disease 2019 (COVID-19) from Publicly Reported Confirmed Cases: Estimation and Application.” Annals of Internal Medicine (2020).

Leary, Alex. 2021. Trump Tells Rioters, 'I Know How You Feel,’ Draws Bipartisan Condemnation. January 7, 2021. The Wall Street Journal. https://www.wsj.com/articles/trump-tells-rioters-i-know-how-you-feel-draws-bipartisancondemnation-11609977209

Mandavilli, Apoorva. 2021. A Riot Amid a Pandemic: Did the Virus, Too, Storm the Capitol? January 7, 2021. The New York Times. https://www.nytimes.com/2021/01/07/health/coronavirus-capitol-riot.html

Mangrum, Daniel, and Paul Niekamp. 2020. JUE Insight: College Student Travel Contributed to Local COVID-19 Spread. Journal of Urban Economics, 103311.

Office of the Mayor. 2021. Mayor’s Order 2020-127. Washington, D.C. https://coronavirus.dc.gov/sites/default/files/dc/sites/coronavirus/page_content/attachmen ts/Mayor\%27s\%20Order\%20127\%2012-18-2020.pdf

Peñaloza, Marisa. Trump Supporters Storm U.S. Capitol, Clash With Police. January 6, 2021. National Public Radio. https://www.npr.org/sections/congress-electoral-college-tallylive-updates/2021/01/06/953616207/diehard-trump-supporters-gather-in-the-nationscapital-to-protest-election-resul

Reuters Staff. 2021. Fact check: Protestors did not 'storm' Georgia and Kansas statehouses. January 8, 2021. Reuters. https://www.reuters.com/article/uk-factcheck-ks-ga-capitolsnot-stormed/fact-check-protestors-did-not-storm-georgia-and-kansas-statehousesidUSKBN29D1YV

Roman, C.G. and Chalfin, A., 2008. "Fear of Walking Outdoors: A Multilevel Ecologic Analysis of Crime and Disorder.” American Journal of Preventive Medicine, 34(4), pp.306-312.

Safdar, Khadeeja, Erin Ailworth, and Deepa Seetharaman. 2021. Police Identify Five Dead After Capitol Riot. January 8, 2021. The Wall Street Journal. https://www.wsj.com/articles/police-identify-those-killed-in-capitol-riot-11610133560

Sardarizadeh, Shayan and Jessica Lussenhop. 2021. Trump riots: 65 days that led to the chaos at the Capitol. January 10, 2021. BBC News. https://www.bbc.com/news/world-us-canada55592332 
Shear, Michael. 2021. Biden calls on Trump to go on national television and 'demand an end to this siege.' January 6, 2021. The New York Times.

https://www.nytimes.com/live/2021/01/06/us/electoral-vote

Stafford, M., Cummins, S., Ellaway, A., Sacker, A., Wiggins, R.D. and Macintyre, S., 2007. Pathways to obesity: identifying local, modifiable determinants of physical activity and diet. Social Science \& Medicine, 65(9), pp.1882-1897.

Stolzenberg, L., D’Alessio, S.J. and Flexon, J.L., 2019. The Impact of Violent Crime on Obesity. Social Sciences, 8(12), p.329.

U.S. Census Bureau. 2010. Decennial Census. Washington, D.C. https://www.icip.iastate.edu/tables/population/urban-pct-states

U.S. Census Bureau. 2019. U.S. Census Bureau Quick Facts. Washington, D.C. https://www.census.gov/quickfacts/DC

U.S. Department of Justice. 2021. U.S. Office of Public Affairs Press Release. January 14, 2021. https://www.justice.gov/opa/pr/acting-attorney-general-jeffrey-rosen-attends-securitybriefing-fbi-s-strategic-information

Wei, J. and Li, Y., 2016. "Airborne spread of infectious agents in the indoor environment.” American Journal of Infection Control, 44(9), pp. S102-S108.

Wing, C., Simon, D.H., and Carlin, P. 2020. "Effects of Large Gatherings on the COVID-19 Epidemic: Evidence from Professional and College Sports.” Available at SSRN: https://ssrn.com/abstract=3657625.

Yu, E. and Lippert, A.M., 2016. Neighborhood crime rate, weight-related behaviors, and obesity: a systematic review of the literature. Sociology Compass, 10(3), pp.187-207.

Zraick, Karen and Rebecca Robbins. 2021. As U.S. tops 4,000 deaths in a day, a record, Fauci warns that January will get harder. January 7, 2021. The New York Times. https://www.nytimes.com/2021/01/07/world/fauci-coronavirus-january.html 
Figure 1. Distribution of Log Smartphone Pings Around the Capitol Riot, January 1, 2021 through January 11, 2021

Panel (a) Total Smartphone Pings

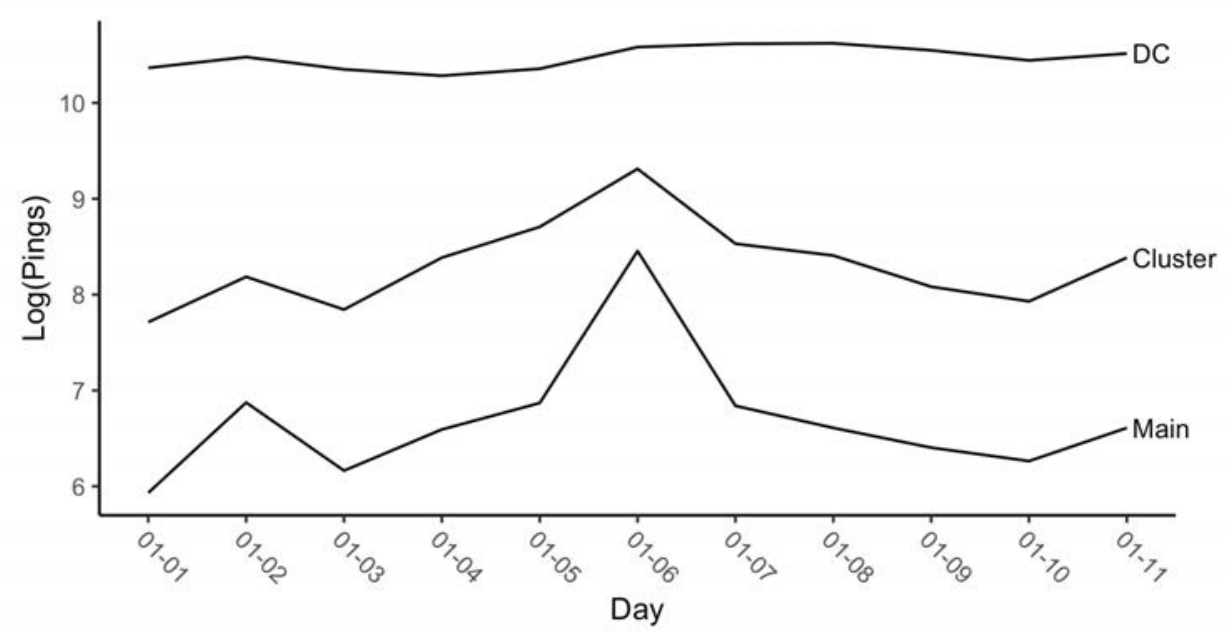

\section{Panel (b) Non-Resident Smartphone Pings}

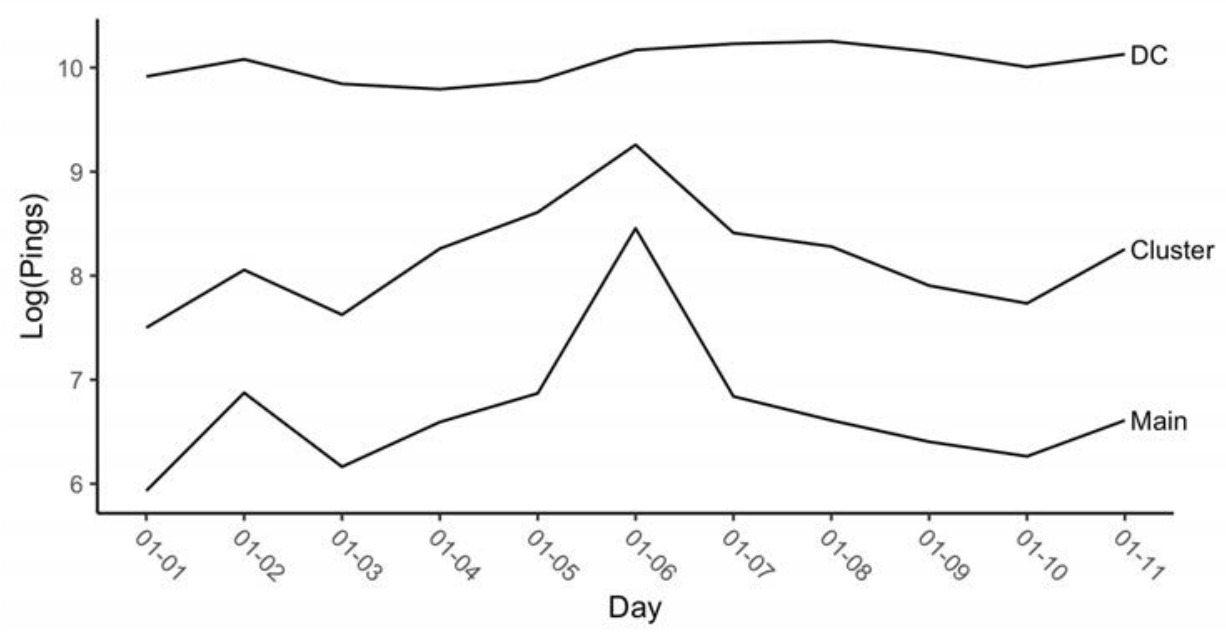

Notes: "D.C.” refers to all census block groups (CBGs) within the District of Columbia, "Cluster" refers to the CBGs that include the Ellipse, the White House, the National Mall and all border CBGs. "Main" refers to the CBG that includes the Ellipse, the White House, and the National Mall. 
Figure 2. Distribution of Home Counties for Smartphones that "Pinged" in the Protest CBG on January 4, 6, and 8, 2021: Absolute Measure

Panel (a): January 4, 2021 (Before Riot)
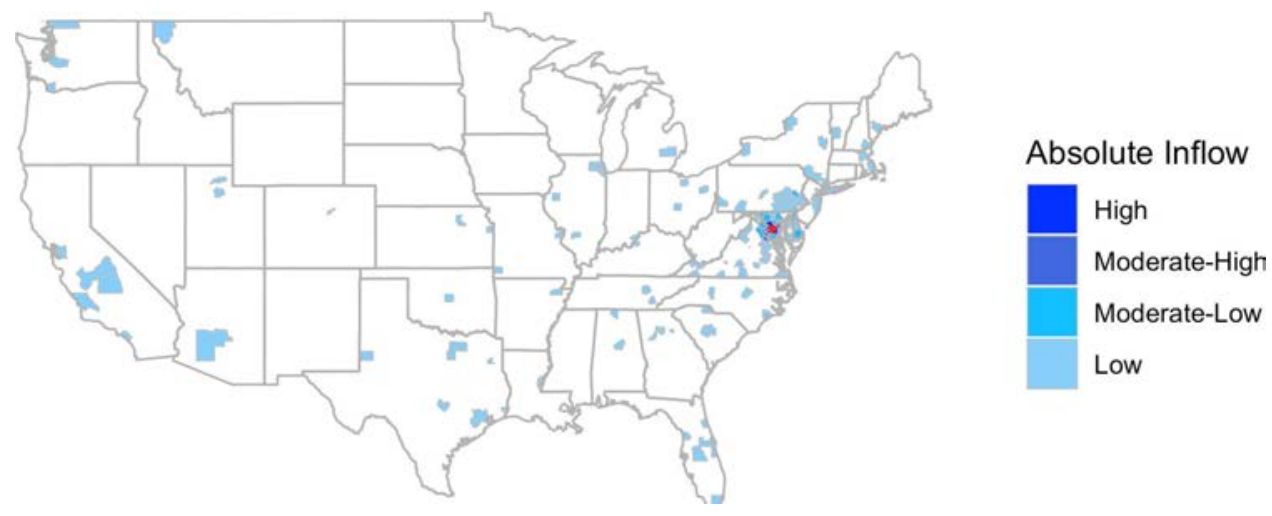

Panel (b): January 6, 2021 (Day of Capitol Riot)
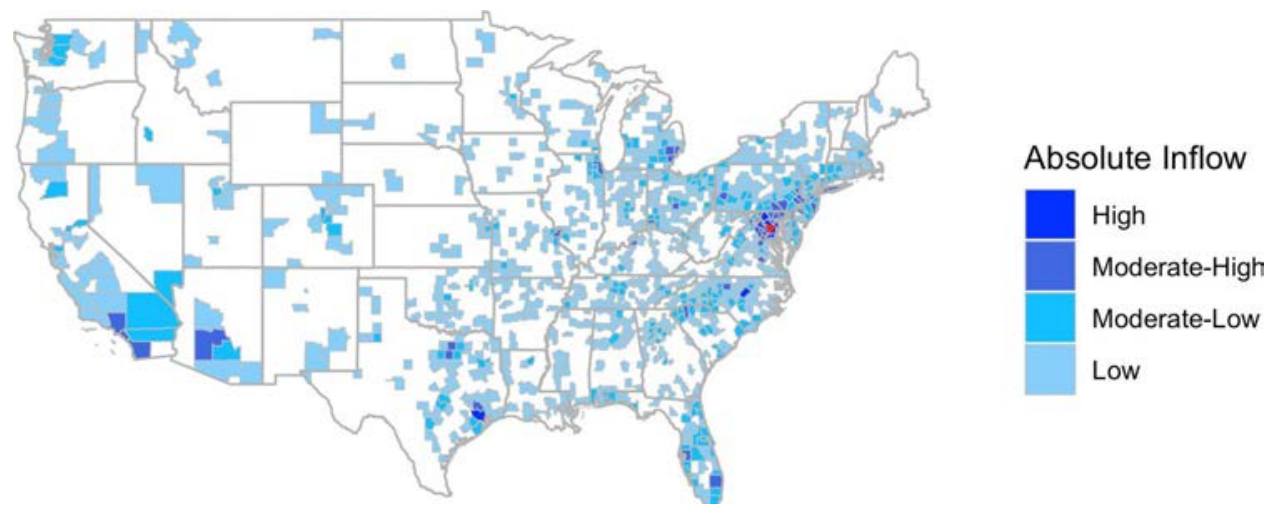

Panel (c): January 8, 2021 (After Riot)

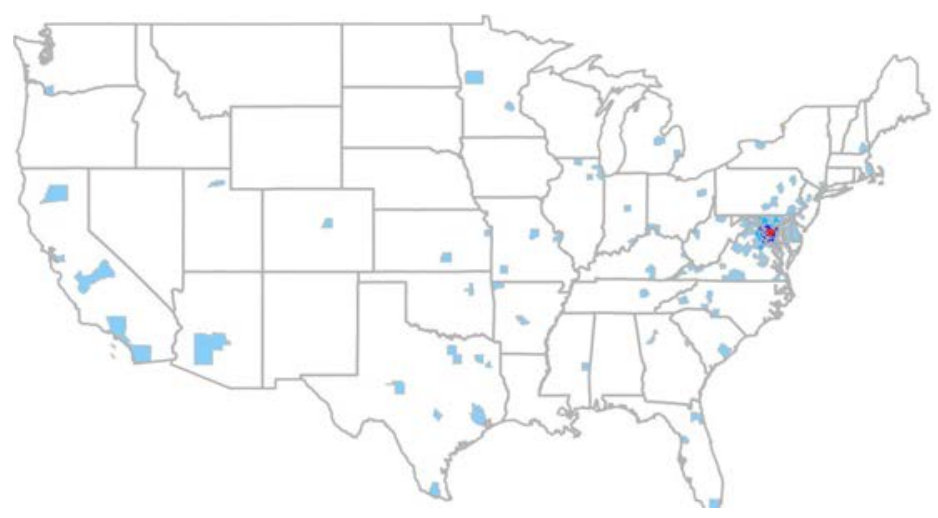

Absolute Inflow

High

Moderate-High

Moderate-Low

Low 
Figure 3. Distribution of Home Counties for Smartphones that "Pinged" in the Protest CBG on January 4, 6, and 8, 2021: Relative Measure

Panel (a): January 4 (Before Riot)

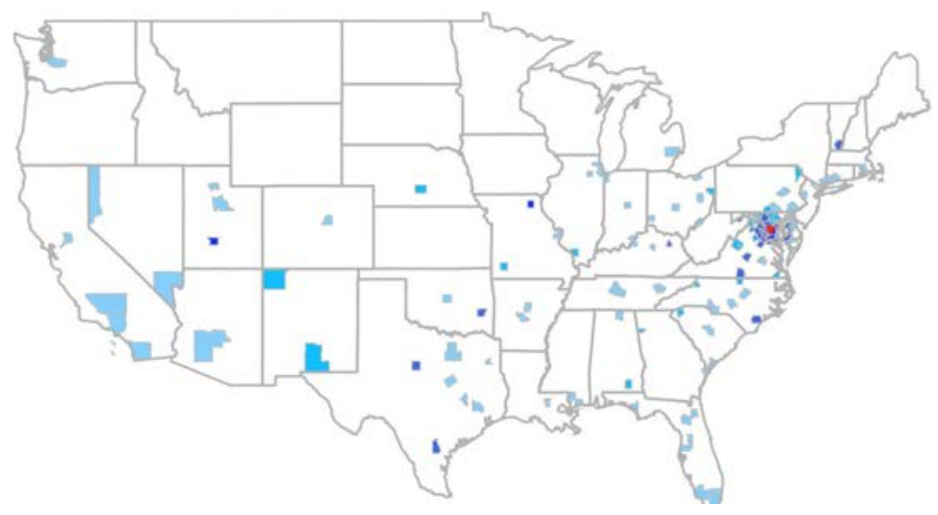

Relative Inflow

Panel (b): January 6 (Day of Riot)

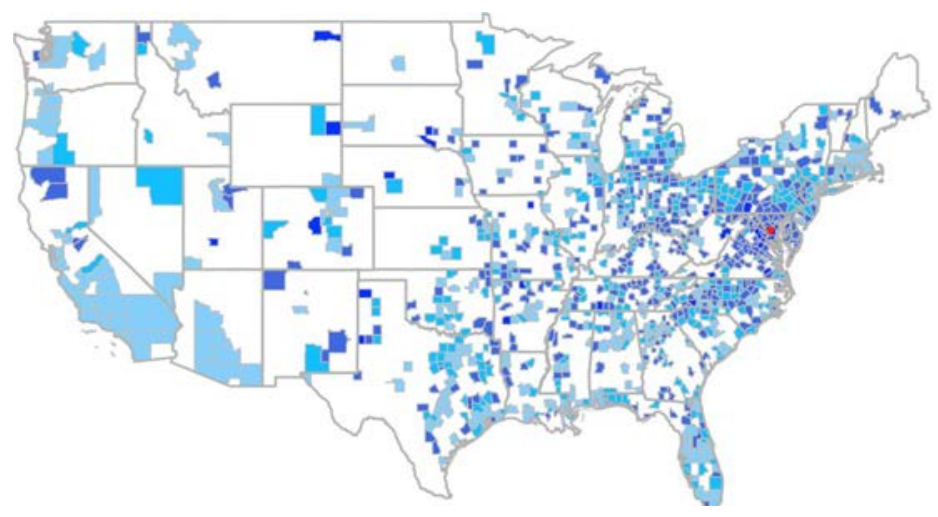

Relative Inflow

High

Moderate-High

Moderate-Low

Low

Panel (c): January 8(After Riot)

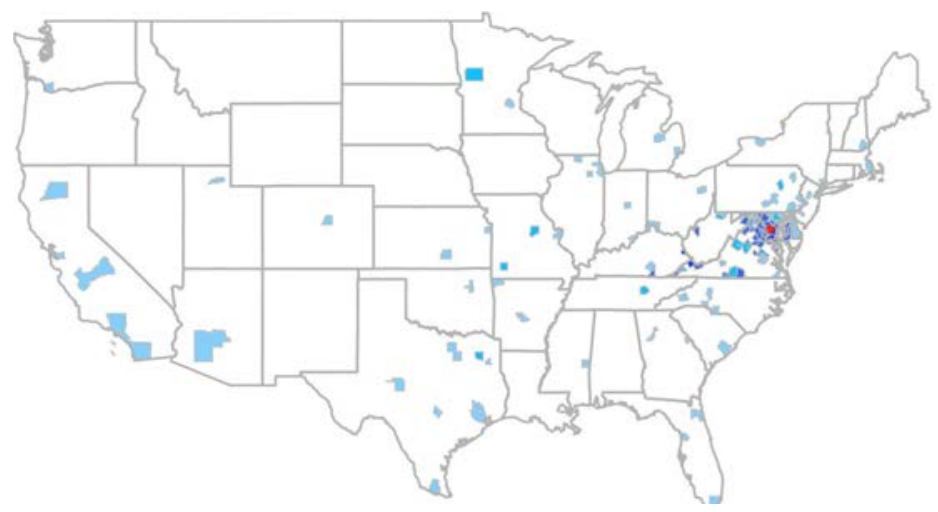

Relative Inflow

High

Moderate-High

Moderate-Low

Low 
Figure 4. Trends in COVID-19 Cases, by “Absolute” County Inflows into the District of Columbia on January 6, 2021

Panel (a): Cumulative COVID-19 Case Rate

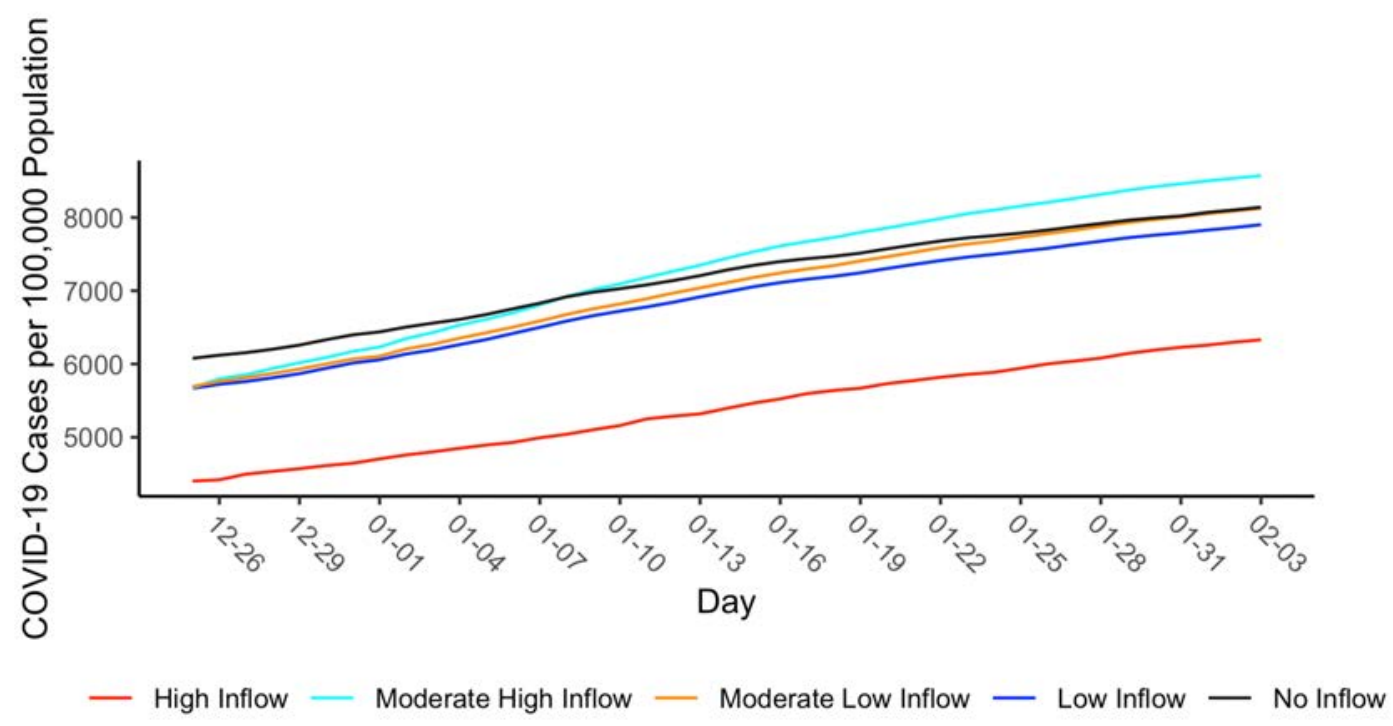

Panel (b): Daily Cumulative COVID-19 Case Growth

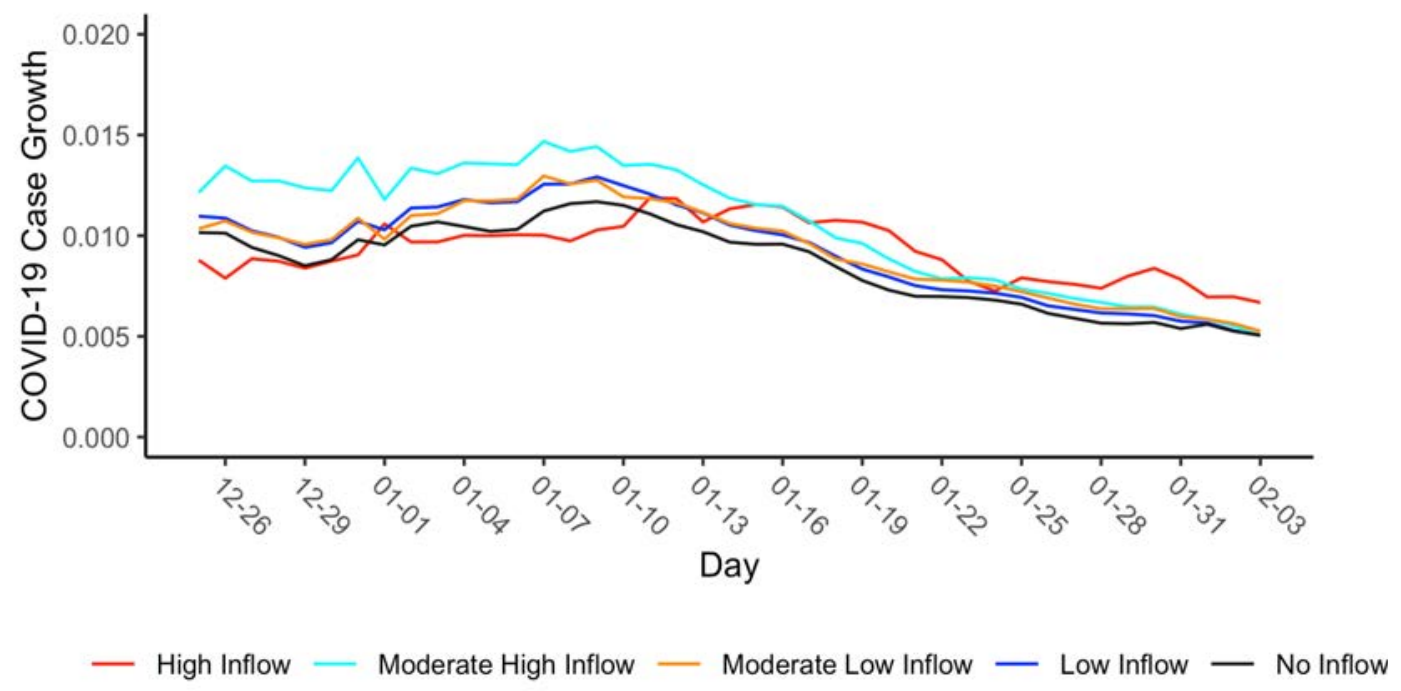


Figure 5. Event-Study Analyses of the Effects of the January 6 Capitol Riot on Log of Total Smartphone Pings and Non-Resident Smartphone Pings in Protest CBG Relative to Other D.C. CBGs

Panel (a): Total Pings (Full D.C. Sample)

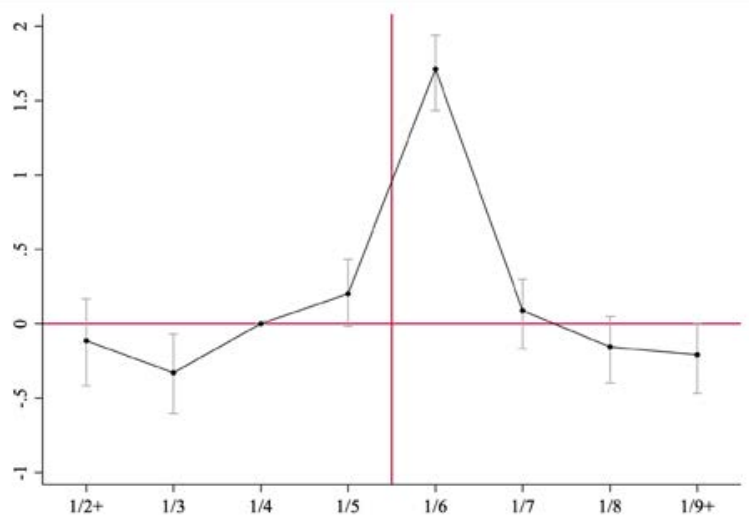

Panel (c): Total Pings (Exclude Border CBGs)

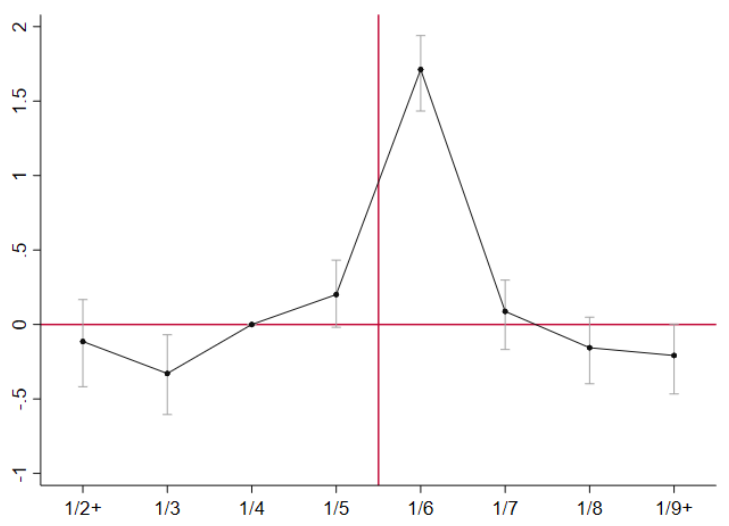

Panel (b): Non-Resident Pings (Full D.C. Sample)

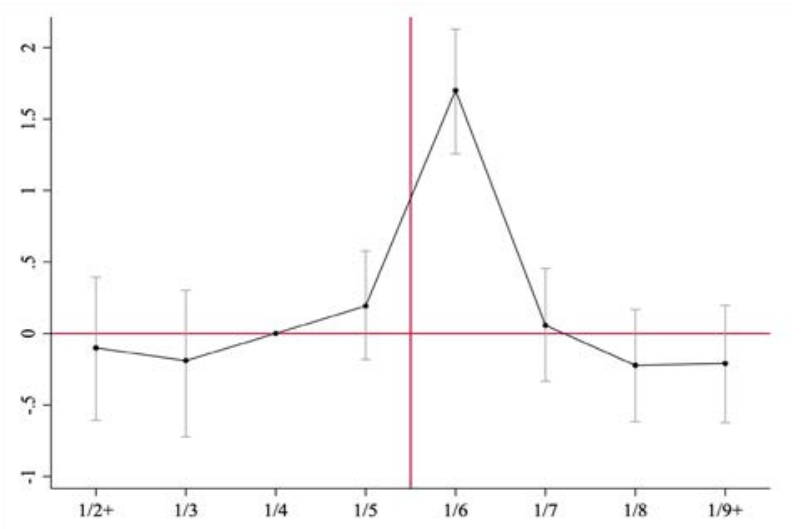

Panel (d): Non-Resident Pings (Exclude Border CBGs)

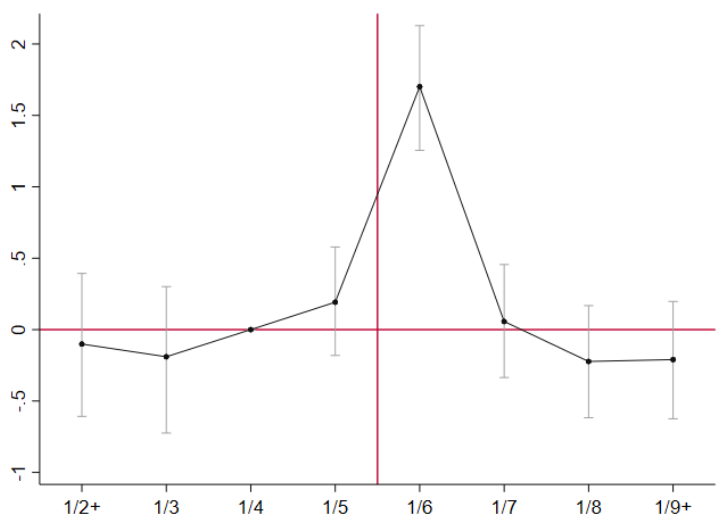




\section{Figure 6. Synthetic Control Estimates of Effect of Capitol Riot on Stay-at-Home Behavior in the District of Columbia}

Panel (a): Percent Home Full-Time - Match on All Pre-Treatment Days

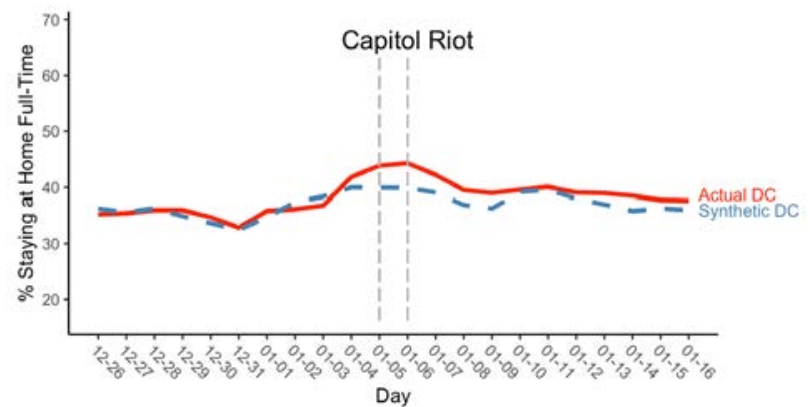

Note: Synthetic D.C. is comprised of San Francisco County, CA (56.4\%), Val Verde County, TX (19.4\%), Denver County, CO (15.5\%), and Sarpy County, NE (4.8\%)

Panel (c): Percent Home Full-Time - Match on 1/2 Pre-Treatment Days and All Observable Controls

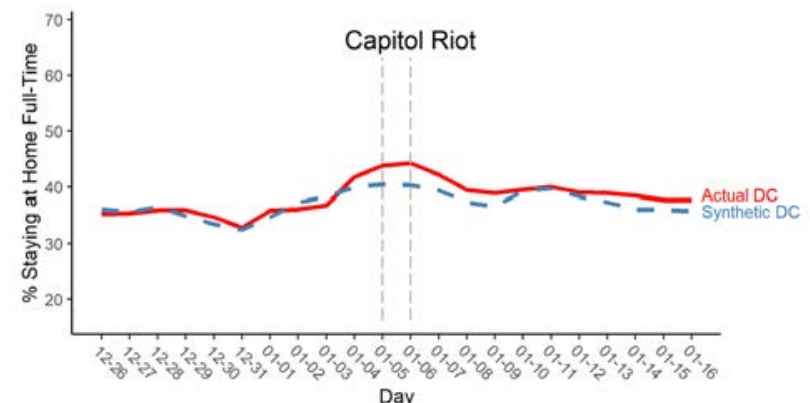

Note: Synthetic D.C. is comprised of San Francisco County, CA (54.5\%), Denver County, CO (24.1\%), and Val Verde County, TX (21.4\%).
Panel (b): Median Percent Time Home - Match on All Pre-Treatment Days

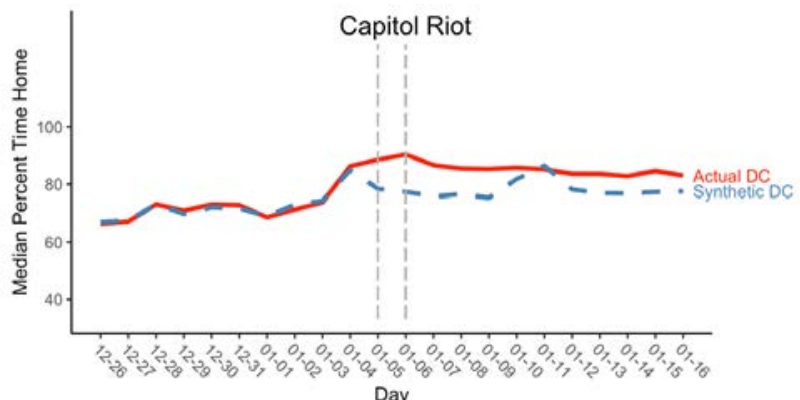

Note: Synthetic D.C. is comprised of Grand Forks County, ND (24\%), Kings County, CA (22.4\%), San Francisco County, CA (22.4\%), Story County, IA (16.3\%), Riley County, KS (7.3\%), Albany County, WY (5.8\%), and Jim Hogg County, TX (1.8\%).

Panel (d): Median Percent Time Home - Match on 1/2 Pre-Treatment Days and All Observable Controls

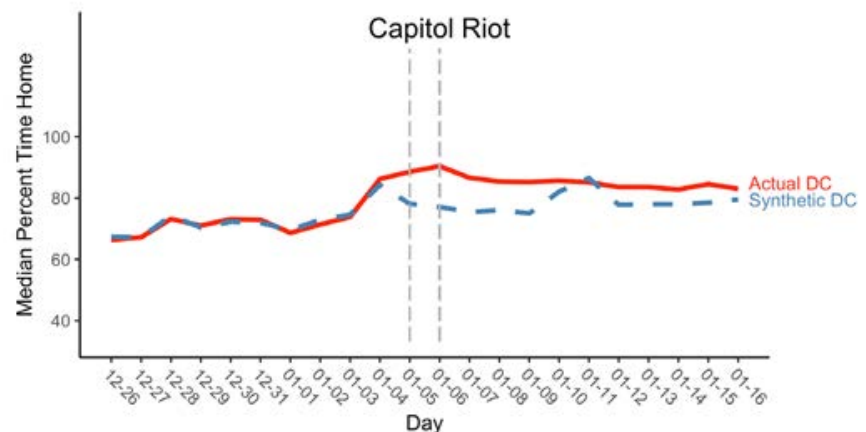

Note: Synthetic D.C. is comprised of Grand Forks County, ND (41.5\%), San Francisco County, CA (40.1\%), and Story County, IA (18.2\%).

Notes: The donor pool is comprised of counties with urbanicity rate of $80 \%$ or higher, and excludes counties in border states, as well as counties with any home residents that pinged in the census block group of the United States Capitol Building on 1/6. Panels (a) and (b) are generated by matching on all pre-treatment days, and panels (c) and (d) are generated by matching on 5 pre-treatment days plus urbanicity, weighted population density, mask wearing mandate, restrictions on bars/restaurants, curfew mandate, and stay-at-home advisory. 
Figure 7. Synthetic Control Estimates of Effect of Capitol Riot on Cumulative COVID-19 Cases Per 100,000 Population in D.C.

Panel (a): Cumulative COVID-19 Cases Per 100,000 Population Match on All Pre-Treatment Days

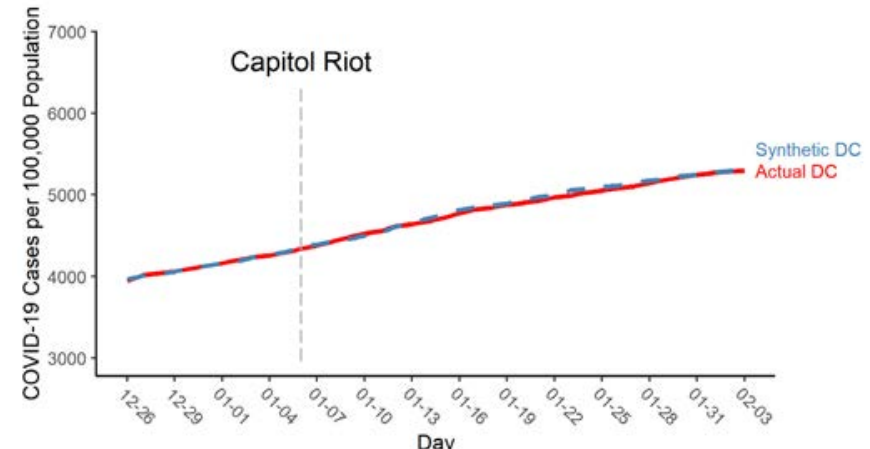

Day

Note: Synthetic D.C. is comprised of Kauai County, HI (24.5\%), Sonoma County, CA (17.6\%), St. Charles Parish, LA (13.3\%), San Patricio County, TX (12.1\%), and Polk County, OR (3.1\%).
Panel (b): Cumulative COVID-19 Cases Per 100,000 Population Match on $1 / 2$ of Pre-Treatment Days and All Observable Controls

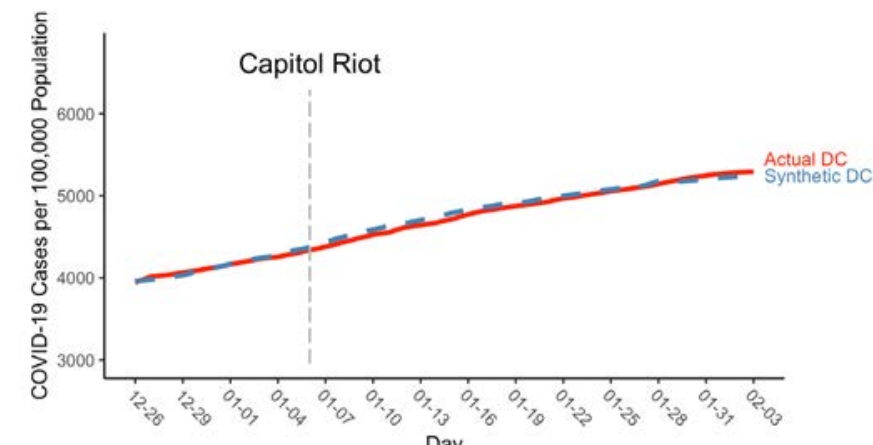

Note: Synthetic D.C. is comprised of San Francisco, CA (55.3\%), Denver County, CO (32.4\%), Asotin County, WA(7.6\%), and Schenectady County, NY (4.5\%).

Panel (c): Cumulative COVID-19 Cases Per 100,000 Population -

Match on $1 / 2$ of Pre-Treatment Days and All Observable Controls \& Exclude State Capitol Counties from Donor Pool

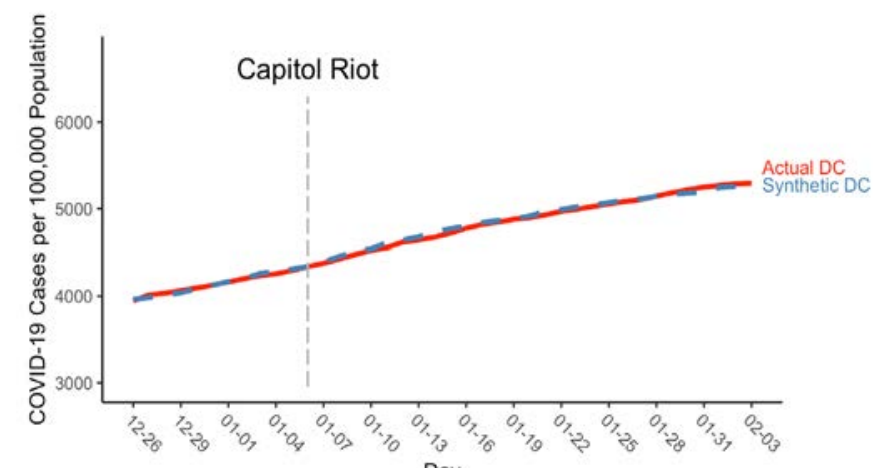

Notes: The donor pool is comprised of counties with urbanicity rate above $80 \%$, and excludes counties in border states, as well as counties with any home residents that pinged in the census block group of the United States Capitol Building on 1/6. Panel (a) is generated by matching on all pre-treatment days, and panel (b) is generated by matching on 5 pre-treatment days plus urbanicity, weighted population density, mask wearing mandate, restrictions on bars/restaurants, curfew mandate, and stay-at-home advisory. 
Figure 8. Event-Study Analysis of Effect of Capitol Riot on Daily Rate of Cumulative COVID-19 Case Growth, by Absolute Inflow of County Residents to Protest CBG on January 6

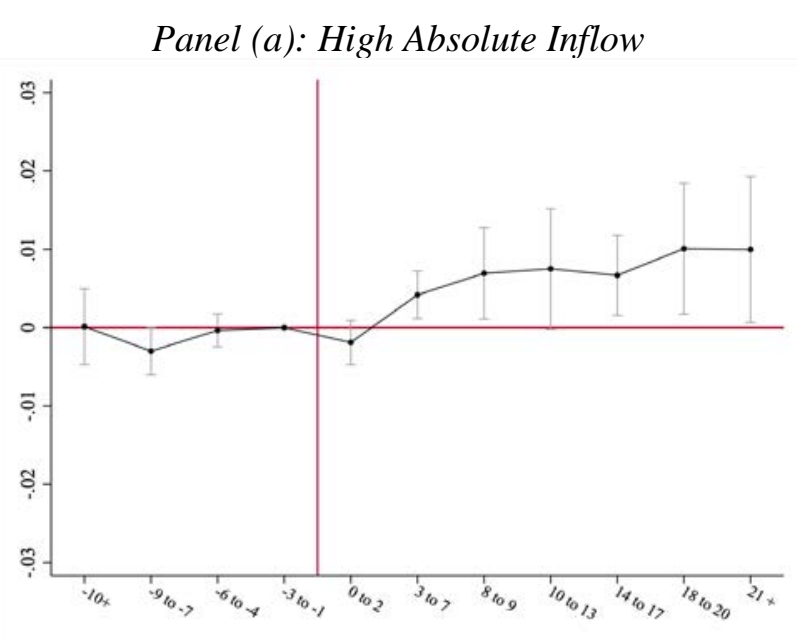

Days Before/After Capitol Riot

Panel (d): Moderate Absolute Inflow

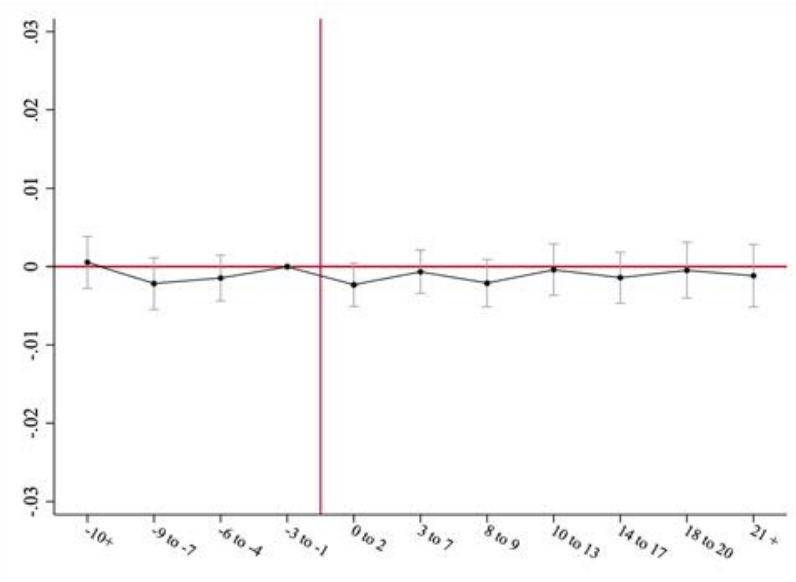

Days Before/After Capitol Riot
Panel (b): Moderate-High Absolute Inflow

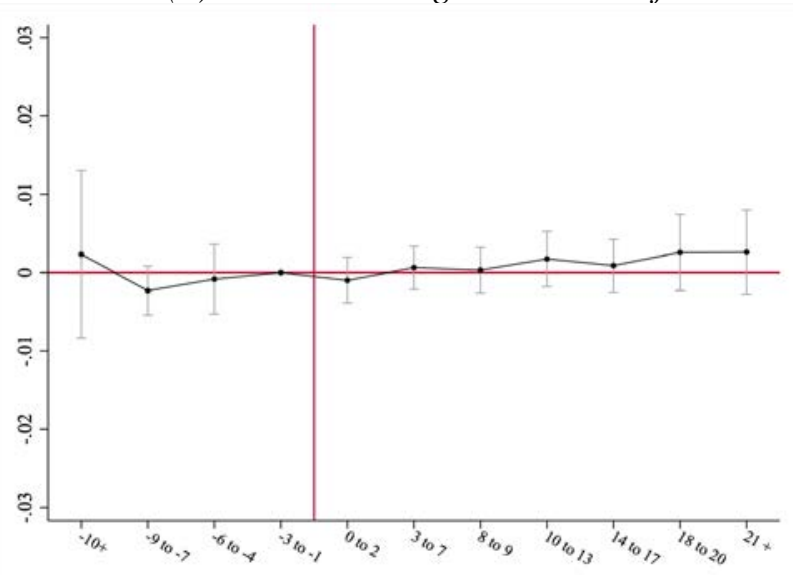

Days Before/After Capitol Riot

Panel (d): Low Absolute Inflow

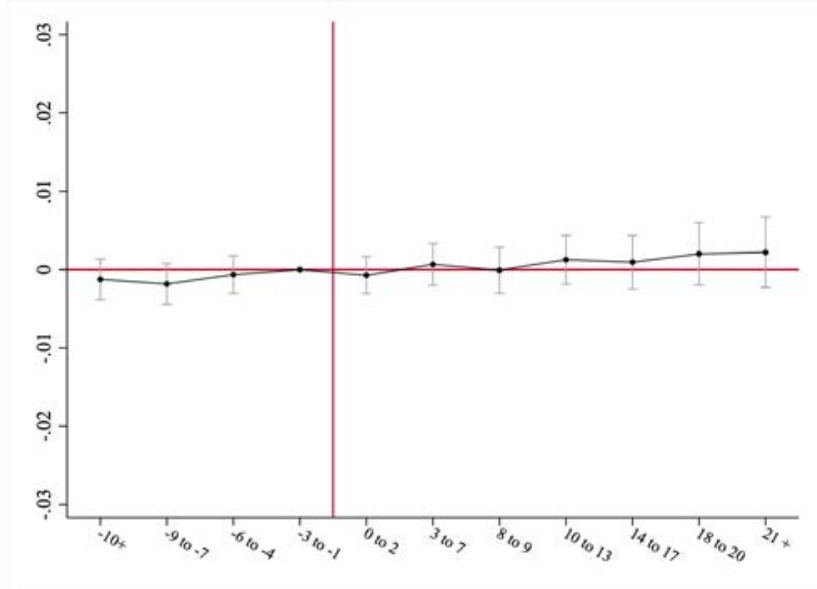

Days Before/After Capitol Riot 
Figure 9. Event-Study Analysis of Effect of Capitol Riot on Daily Rate of Cumulative COVID-19 Case Growth, by Relative Inflow of County Residents to Protest CBG on January 6

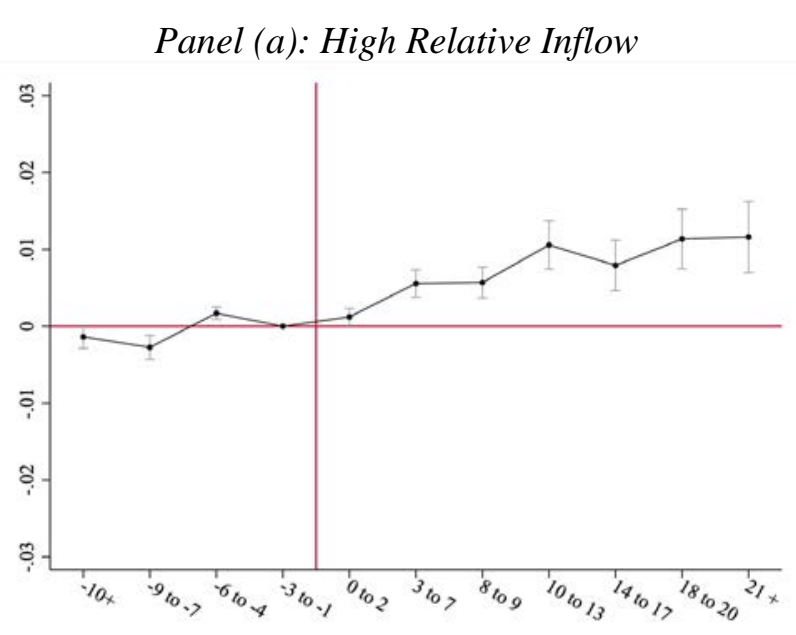

Days Before/After Capitol Riot

Panel (d): Moderate Relative Inflow

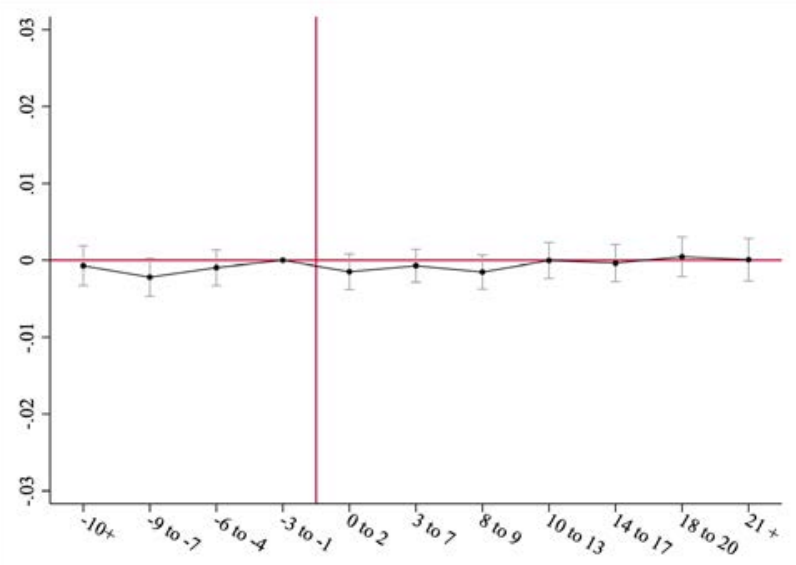

Days Before/After Capitol Riot
Panel (b): Moderate-High Relative Inflow

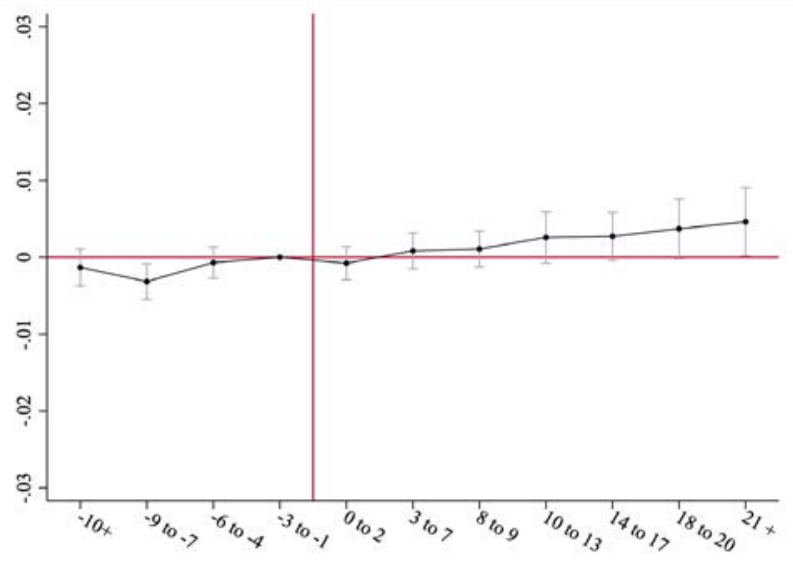

Days Before/After Capitol Riot

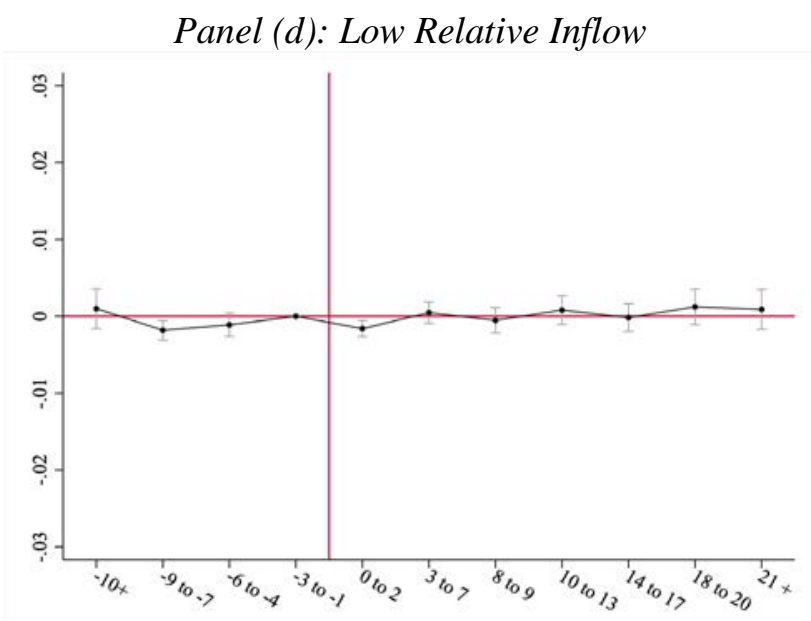

Days Before/After Capitol Riot 


\section{Table 1. Difference-in-Differences Estimates of Effect of the Capitol Riot on Log Smartphone Pings in Treatment Census Block Group}

\section{(1)}

Total Smartphone Pings
(3)

(4)

Panel I: Sample: All District of Columbia CBGs

\begin{tabular}{|c|c|c|c|c|}
\hline & & & & \\
\hline January $6^{\text {th }}$ & $\begin{array}{c}1.755^{* * *} \\
{[\mathrm{p}=0.0023]}\end{array}$ & $\begin{array}{c}1.654 * * * \\
{[\mathrm{p}=0.0046]}\end{array}$ & $\begin{array}{c}1.709 * * * \\
{[\mathrm{p}=0.0069]}\end{array}$ & $\begin{array}{c}1.614 * * * \\
{[\mathrm{p}=0.0046]}\end{array}$ \\
\hline January 7+ & -0.07 & -0.271 & -0.121 & -0.311 \\
\hline & {$[\mathrm{p}=0.6528]$} & {$[\mathrm{p}=0.8773]$} & {$[\mathrm{p}=0.6968]$} & {$[\mathrm{p}=0.8032]$} \\
\hline Observations & 4,950 & 4,950 & 4,950 & 4,950 \\
\hline & Pan & Sample: Excl & rder CBGs to & st $C B G$ \\
\hline January $6^{\text {th }}$ & $\begin{array}{c}1.783^{* * *} \\
{[\mathrm{p}=0.0023]}\end{array}$ & $\begin{array}{c}1.678 * * * \\
{[\mathrm{p}=0.0046]}\end{array}$ & $\begin{array}{c}1.741 * * * \\
{[\mathrm{p}=0.0046]}\end{array}$ & $\begin{array}{c}1.635 * * * \\
{[\mathrm{p}=0.0046]}\end{array}$ \\
\hline January $7+$ & $\begin{array}{c}-0.067 \\
{[p=0.6458]}\end{array}$ & $\begin{array}{c}-0.277 \\
{[p=0.8796]}\end{array}$ & $\begin{array}{c}-0.119 \\
{[p=0.6898]}\end{array}$ & $\begin{array}{c}-0.333 \\
{[p=0.8125]}\end{array}$ \\
\hline Observations & 4,752 & 4,752 & 4,752 & 4,752 \\
\hline CBG Linear Time Trend? & No & Yes & No & Yes \\
\hline
\end{tabular}

$* * *$ Significant at $1 \%$ level **at $5 \%$ level *at $10 \%$ level

Notes: Estimates are generated using ordinary least squares. All models include cluster and day fixed effects.

Permutation based p-value is reported inside the bracket 
Table 2. Synthetic Control Estimates of Effect of Capitol Riot on Stay-at-Home Behavior Among Local Residents in District of Columbia

\begin{tabular}{|c|c|c|c|c|c|c|c|c|}
\hline & \multicolumn{4}{|c|}{ Percent Staying at Home Full-Time } & \multicolumn{4}{|c|}{ Median Percent Time at Home } \\
\hline & (1) & $(2)$ & (3) & (4) & (5) & (6) & (7) & $(8)$ \\
\hline & \multicolumn{8}{|c|}{ Panel I: Full Post-Treatment Period } \\
\hline Capitol Riot & 2.216 & 1.946 & 1.949 & 2.242 & 7.143 & $5.508 *$ & $6.876^{*}$ & $7.633 * *$ \\
\hline P-Value & {$[0.826]$} & {$[0.716]$} & {$[0.688]$} & {$[0.689]$} & {$[0.431]$} & {$[0.165]$} & {$[0.083]$} & {$[0.047]$} \\
\hline One Sided P-Value & [0.394] & {$[0.367]$} & [0.349] & {$[0.377]$} & [0.165] & {$[0.092]$} & {$[0.055]$} & {$[0.028]$} \\
\hline \multirow[t]{2}{*}{ Pre-Treatment Mean of DV } & 36.06 & 36.06 & 36.06 & 36.06 & 72.38 & 72.38 & 72.38 & 72.38 \\
\hline & \multicolumn{8}{|c|}{ Panel II: Lagged Post-Treatment Windows } \\
\hline Capitol Riot (1/5 to $1 / 6)$ & 4.154 & 3.641 & 3.644 & 4.502 & 11.558 & $9.655^{* *}$ & $11.876^{* *}$ & $12.321^{* *}$ \\
\hline P-Value & {$[0.606]$} & {$[0.394]$} & {$[0.367]$} & {$[0.349]$} & [0.321] & {$[0.073]$} & {$[0.037]$} & {$[0.038]$} \\
\hline One Sided P-Value & {$[0.303]$} & {$[0.211]$} & {$[0.202]$} & {$[0.189]$} & {$[0.119]$} & {$[0.037]$} & {$[0.028]$} & {$[0.028]$} \\
\hline Capitol Riot $(1 / 7+)$ & 1.828 & 1.607 & 1.609 & 1.79 & 6.26 & 4.679 & $5.876^{*}$ & $6.696 * *$ \\
\hline P-Value & [0.853] & {$[0.789]$} & {$[0.780]$} & {$[0.755]$} & {$[0.450]$} & {$[0.220]$} & {$[0.092]$} & {$[0.075]$} \\
\hline One Sided P-Value & {$[0.422]$} & {$[0.404]$} & {$[0.385]$} & {$[0.406]$} & {$[0.165]$} & [0.119] & {$[0.064]$} & {$[0.038]$} \\
\hline Pre-Treatment Mean of DV & 36.06 & 36.06 & 36.06 & 36.06 & 72.38 & 72.38 & 72.38 & 72.38 \\
\hline \multicolumn{9}{|l|}{ Matching Variables } \\
\hline All Pre-Treatment Days & $\mathrm{Y}$ & $\mathrm{N}$ & $\mathrm{N}$ & $\mathrm{N}$ & $\mathrm{Y}$ & $\mathrm{N}$ & $\mathrm{N}$ & $\mathrm{N}$ \\
\hline $\begin{array}{l}\text { Match on } 12 / 27,12 / 29,12 / 31,1 / 2,1 / 4 \\
\text { Outcome, Urbanicity, Restaurant/Bar Closure }\end{array}$ & $\mathrm{N}$ & $\mathrm{Y}$ & $\mathrm{Y}$ & $\mathrm{Y}$ & $\mathrm{N}$ & $\mathrm{Y}$ & $\mathrm{Y}$ & $\mathrm{Y}$ \\
\hline $\begin{array}{l}\text { Match on Stay-at-Home Advisory, Mask } \\
\text { Mandate, Curfew Mandate }\end{array}$ & $\mathrm{N}$ & $\mathrm{N}$ & $\mathrm{Y}$ & $\mathrm{Y}$ & $\mathrm{N}$ & $\mathrm{N}$ & $\mathrm{Y}$ & $\mathrm{Y}$ \\
\hline State Capitol Counties Omitted & $\mathrm{N}$ & $\mathrm{N}$ & $\mathrm{N}$ & $\mathrm{Y}$ & $\mathrm{N}$ & $\mathrm{N}$ & $\mathrm{N}$ & $\mathrm{Y}$ \\
\hline
\end{tabular}

\footnotetext{
* Significant at the $10 \%$ level; ** Significant at the $5 \%$ level; *** Significant at the $1 \%$ level

Notes: The donor pool is comprised of counties with urbanicity rate above $80 \%$, and excludes counties in border states, as well as counties with greater than 1 home resident that pinged in the census block group of the United States Capitol Building on 1/6.
} 
Table 3. Synthetic Control Estimates of Effect of Capitol Riot on Cumulative COVID-19 Cases Per 100,000 Population in DC

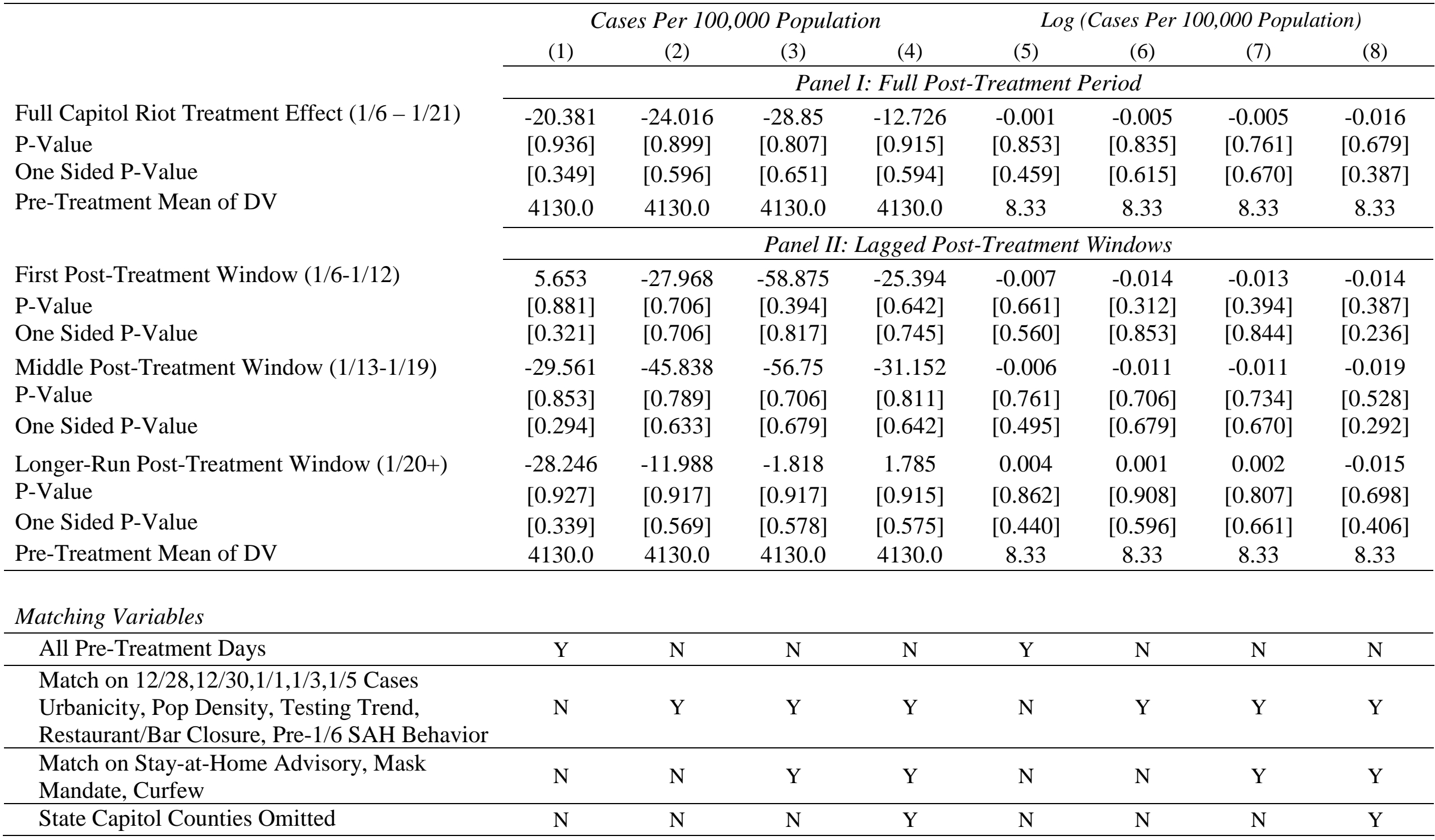

* Significant at the $10 \%$ level; ** Significant at the $5 \%$ level; *** Significant at the $1 \%$ level

Notes: The donor pool is comprised of counties with urbanicity rate above $80 \%$, and excludes counties in border states, as well as counties with greater than 1 home resident that pinged in the census block group of the United States Capitol Building on 1/6. 
Table 4. Dose-Response "Difference-in-Differences” Estimates of the Effect of the Capitol Riot on Daily Rate of Cumulative COVID-19 Case Growth

\begin{tabular}{|c|c|c|c|c|c|c|}
\hline \multirow{3}{*}{ Counties with High Inflow } & \multicolumn{3}{|c|}{ Absolute Inflow } & \multicolumn{3}{|c|}{ Relative Inflow } \\
\hline & $(1)$ & $(2)$ & $(3)$ & $(4)$ & $(5)$ & $(6)$ \\
\hline & & & & & & \\
\hline January 6-8 (0-2 Days After Capitol Riot) & $\begin{array}{l}-0.0019 \\
(0.0014)\end{array}$ & $\begin{array}{c}-0.0018 \\
(0.0014)\end{array}$ & $\begin{array}{l}-0.0012 \\
(0.0008)\end{array}$ & $\begin{array}{c}0.001 \\
(0.001)\end{array}$ & $\begin{array}{c}0.0013 \\
(0.0009)\end{array}$ & $\begin{array}{c}0.0008 \\
(0.0007)\end{array}$ \\
\hline January 9-13 (3-7 Days After Capitol Riot) & $\begin{array}{c}0.0042^{* *} \\
(0.0015)\end{array}$ & $\begin{array}{c}0.0044 * * \\
(0.0015)\end{array}$ & $\begin{array}{c}0.0051^{* * * *} \\
(0.0007)\end{array}$ & $\begin{array}{c}0.006^{* * *} \\
(0.002)\end{array}$ & $\begin{array}{c}0.0057 * * * \\
(0.0015)\end{array}$ & $\begin{array}{c}0.0051^{* * *} \\
(0.0013)\end{array}$ \\
\hline January 14-15 (8-9 Days After Capitol Riot) & $\begin{array}{l}0.0069 * \\
(0.0029)\end{array}$ & $\begin{array}{c}0.0073^{*} \\
(0.0029)\end{array}$ & $\begin{array}{c}0.0083^{* *} \\
(0.0026)\end{array}$ & $\begin{array}{c}0.006^{* *} \\
(0.002)\end{array}$ & $\begin{array}{c}0.0060^{* *} \\
(0.0017)\end{array}$ & $\begin{array}{c}0.0053^{* *} \\
(0.0016)\end{array}$ \\
\hline January 16-19 (10-13 Days After Capitol Riot) & $\begin{array}{c}0.0075 \\
(0.0038)\end{array}$ & $\begin{array}{l}0.0079 * \\
(0.0037)\end{array}$ & $\begin{array}{c}0.0106 * * * \\
(0.0020)\end{array}$ & $\begin{array}{c}0.011^{* * *} \\
(0.003)\end{array}$ & $\begin{array}{c}0.0109 * * * \\
(0.0027)\end{array}$ & $\begin{array}{c}0.0104 * * * \\
(0.0028)\end{array}$ \\
\hline January 20-23 (14-17 Days After Capitol Riot) & $\begin{array}{l}0.0067^{*} \\
(0.0025)\end{array}$ & $\begin{array}{l}0.0071 * * \\
(0.0025)\end{array}$ & $\begin{array}{l}0.0082 * * * \\
(0.0014)\end{array}$ & $\begin{array}{c}0.008 * * \\
(0.003)\end{array}$ & $\begin{array}{l}0.0082 * * \\
(0.0028)\end{array}$ & $\begin{array}{c}0.0072 * * \\
(0.0025)\end{array}$ \\
\hline January 24-26 (18-20 Days After Capitol Riot) & $\begin{array}{l}0.0101^{*} \\
(0.0042)\end{array}$ & $\begin{array}{l}0.0105^{*} \\
(0.0041)\end{array}$ & $\begin{array}{l}0.0131^{* * *} \\
(0.0019)\end{array}$ & $\begin{array}{l}0.011^{* *} \\
(0.003)\end{array}$ & $\begin{array}{c}0.0117 * * * \\
(0.0033)\end{array}$ & $\begin{array}{l}0.0108 * * \\
(0.0033)\end{array}$ \\
\hline January 27+ (21+ Days After Capitol Riot) & $\begin{array}{l}0.0100 * \\
(0.0046)\end{array}$ & $\begin{array}{l}0.0104^{*} \\
(0.0045)\end{array}$ & $\begin{array}{c}0.0132 * * * \\
(0.0021)\end{array}$ & $\begin{array}{l}0.012^{* *} \\
(0.004)\end{array}$ & $\begin{array}{l}0.0120 * * \\
(0.0040)\end{array}$ & $\begin{array}{l}0.0106^{* *} \\
(0.0037)\end{array}$ \\
\hline \multicolumn{7}{|l|}{ Counties with Moderate- High Inflow } \\
\hline January 6-8 (0-2 Days After Capitol Riot) & $\begin{array}{l}-0.0010 \\
(0.0015)\end{array}$ & $\begin{array}{c}-0.0009 \\
(0.0015)\end{array}$ & $\begin{array}{l}-0.0004 \\
(0.0014)\end{array}$ & $\begin{array}{c}-0.001 \\
(0.002)\end{array}$ & $\begin{array}{l}-0.0007 \\
(0.0019)\end{array}$ & $\begin{array}{l}-0.0004 \\
(0.0019)\end{array}$ \\
\hline January 9-13 (3-7 Days After Capitol Riot) & $\begin{array}{c}0.0006 \\
(0.0014)\end{array}$ & $\begin{array}{c}0.0009 \\
(0.0014)\end{array}$ & $\begin{array}{c}0.0012 \\
(0.0014)\end{array}$ & $\begin{array}{c}0.001 \\
(0.002)\end{array}$ & $\begin{array}{c}0.0009 \\
(0.0021)\end{array}$ & $\begin{array}{c}0.0011 \\
(0.0021)\end{array}$ \\
\hline January 14-15 (8-9 Days After Capitol Riot) & $\begin{array}{c}0.0003 \\
(0.0015)\end{array}$ & $\begin{array}{c}0.0005 \\
(0.0016)\end{array}$ & $\begin{array}{c}0.0005 \\
(0.0017)\end{array}$ & $\begin{array}{c}0.001 \\
(0.002)\end{array}$ & $\begin{array}{c}0.0012 \\
(0.0021)\end{array}$ & $\begin{array}{c}0.0013 \\
(0.0021)\end{array}$ \\
\hline January 16-19 (10-13 Days After Capitol Riot) & $\begin{array}{c}0.0017 \\
(0.0018)\end{array}$ & $\begin{array}{c}0.0020 \\
(0.0019)\end{array}$ & $\begin{array}{c}0.0023 \\
(0.0019)\end{array}$ & $\begin{array}{c}0.003 \\
(0.003)\end{array}$ & $\begin{array}{c}0.0027 \\
(0.0029)\end{array}$ & $\begin{array}{c}0.0034 \\
(0.0028)\end{array}$ \\
\hline January 20-23 (14-17 Days After Capitol Riot) & $\begin{array}{c}0.0009 \\
(0.0017)\end{array}$ & $\begin{array}{c}0.0012 \\
(0.0018)\end{array}$ & $\begin{array}{c}0.0009 \\
(0.0019)\end{array}$ & $\begin{array}{c}0.003 \\
(0.003)\end{array}$ & $\begin{array}{c}0.0028 \\
(0.0028)\end{array}$ & $\begin{array}{c}0.0031 \\
(0.0028)\end{array}$ \\
\hline January 24-26 (18-20 Days After Capitol Riot) & $\begin{array}{c}0.0026 \\
(0.0024)\end{array}$ & $\begin{array}{c}0.0028 \\
(0.0025)\end{array}$ & $\begin{array}{c}0.0026 \\
(0.0026)\end{array}$ & $\begin{array}{c}0.004 \\
(0.003)\end{array}$ & $\begin{array}{c}0.0039 \\
(0.0034)\end{array}$ & $\begin{array}{c}0.0045 \\
(0.0032)\end{array}$ \\
\hline January 27+ (21+ Days After Capitol Riot) & $\begin{array}{c}0.0026 \\
(0.0027)\end{array}$ & $\begin{array}{c}0.0029 \\
(0.0028)\end{array}$ & $\begin{array}{c}0.0025 \\
(0.0029)\end{array}$ & $\begin{array}{c}0.005 \\
(0.004)\end{array}$ & $\begin{array}{c}0.0048 \\
(0.0038)\end{array}$ & $\begin{array}{c}0.0056 \\
(0.0037)\end{array}$ \\
\hline
\end{tabular}


Counties with Moderate Inflow

\begin{tabular}{|c|c|c|c|c|c|c|}
\hline January 6-8 (0-2 Days After Capitol Riot) & $\begin{array}{c}-0.0023 \\
(0.0014)\end{array}$ & $\begin{array}{c}-0.0022 \\
(0.0014)\end{array}$ & $\begin{array}{c}-0.0024 \\
(0.0015)\end{array}$ & $\begin{array}{c}-0.001 \\
(0.002)\end{array}$ & $\begin{array}{c}-0.0014 \\
(0.0020)\end{array}$ & $\begin{array}{c}-0.0016 \\
(0.0022)\end{array}$ \\
\hline January 9-13 (3-7 Days After Capitol Riot) & $\begin{array}{l}-0.0007 \\
(0.0014)\end{array}$ & $\begin{array}{c}-0.0004 \\
(0.0014)\end{array}$ & $\begin{array}{l}-0.0005 \\
(0.0015)\end{array}$ & $\begin{array}{c}-0.001 \\
(0.002)\end{array}$ & $\begin{array}{l}-0.0005 \\
(0.0019)\end{array}$ & $\begin{array}{l}-0.0009 \\
(0.0020)\end{array}$ \\
\hline January 14-15 (8-9 Days After Capitol Riot) & $\begin{array}{c}-0.0021 \\
(0.0015)\end{array}$ & $\begin{array}{c}-0.0017 \\
(0.0016)\end{array}$ & $\begin{array}{l}-0.0020 \\
(0.0016)\end{array}$ & $\begin{array}{c}-0.002 \\
(0.002)\end{array}$ & $\begin{array}{c}-0.0014 \\
(0.0020)\end{array}$ & $\begin{array}{c}-0.0019 \\
(0.0021)\end{array}$ \\
\hline January 16-19 (10-13 Days After Capitol Riot) & $\begin{array}{l}-0.0004 \\
(0.0016)\end{array}$ & $\begin{array}{c}0.0000 \\
(0.0017)\end{array}$ & $\begin{array}{c}-0.0003 \\
(0.0018)\end{array}$ & $\begin{array}{l}-0.000 \\
(0.002)\end{array}$ & $\begin{array}{c}0.0001 \\
(0.0021)\end{array}$ & $\begin{array}{c}-0.0005 \\
(0.0022)\end{array}$ \\
\hline January 20-23 (14-17 Days After Capitol Riot) & $\begin{array}{l}-0.0014 \\
(0.0016)\end{array}$ & $\begin{array}{l}-0.0010 \\
(0.0017)\end{array}$ & $\begin{array}{c}-0.0013 \\
(0.0018)\end{array}$ & $\begin{array}{c}-0.000 \\
(0.002)\end{array}$ & $\begin{array}{c}-0.0002 \\
(0.0022)\end{array}$ & $\begin{array}{c}-0.0008 \\
(0.0023)\end{array}$ \\
\hline January 24-26 (18-20 Days After Capitol Riot) & $\begin{array}{l}-0.0005 \\
(0.0018)\end{array}$ & $\begin{array}{c}0.0000 \\
(0.0019)\end{array}$ & $\begin{array}{c}-0.0004 \\
(0.0019)\end{array}$ & $\begin{array}{c}0.000 \\
(0.002)\end{array}$ & $\begin{array}{c}0.0007 \\
(0.0023)\end{array}$ & $\begin{array}{c}-0.0001 \\
(0.0024)\end{array}$ \\
\hline $\begin{array}{l}\text { January 27+ (21+ Days After Capitol Riot) } \\
\text { Counties with Low Inflow }\end{array}$ & $\begin{array}{l}-0.0012 \\
(0.0020)\end{array}$ & $\begin{array}{l}-0.0007 \\
(0.0021)\end{array}$ & $\begin{array}{l}-0.0011 \\
(0.0021)\end{array}$ & $\begin{array}{c}0.000 \\
(0.002)\end{array}$ & $\begin{array}{c}0.0004 \\
(0.0025)\end{array}$ & $\begin{array}{l}-0.0005 \\
(0.0025)\end{array}$ \\
\hline January 6-8 (0-2 Days After Capitol Riot) & $\begin{array}{c}-0.0007 \\
(0.0012)\end{array}$ & $\begin{array}{c}-0.0007 \\
(0.0012)\end{array}$ & $\begin{array}{l}-0.0007 \\
(0.0014)\end{array}$ & $\begin{array}{c}-0.002 \\
(0.001)\end{array}$ & $\begin{array}{l}-0.0015 \\
(0.0009)\end{array}$ & $\begin{array}{l}-0.0015 \\
(0.0011)\end{array}$ \\
\hline January 9-13 (3-7 Days After Capitol Riot) & $\begin{array}{c}0.0007 \\
(0.0013)\end{array}$ & $\begin{array}{c}0.0007 \\
(0.0014)\end{array}$ & $\begin{array}{c}0.0007 \\
(0.0015)\end{array}$ & $\begin{array}{c}0.000 \\
(0.001)\end{array}$ & $\begin{array}{c}0.0007 \\
(0.0012)\end{array}$ & $\begin{array}{c}0.0008 \\
(0.0013)\end{array}$ \\
\hline January 14-15 (8-9 Days After Capitol Riot) & $\begin{array}{l}-0.0001 \\
(0.0015)\end{array}$ & $\begin{array}{c}0.0001 \\
(0.0015)\end{array}$ & $\begin{array}{l}-0.0000 \\
(0.0016)\end{array}$ & $\begin{array}{c}-0.001 \\
(0.001)\end{array}$ & $\begin{array}{l}-0.0002 \\
(0.0015)\end{array}$ & $\begin{array}{c}-0.0002 \\
(0.0016)\end{array}$ \\
\hline January 16-19 (10-13 Days After Capitol Riot) & $\begin{array}{c}0.0013 \\
(0.0016)\end{array}$ & $\begin{array}{c}0.0014 \\
(0.0016)\end{array}$ & $\begin{array}{c}0.0014 \\
(0.0018)\end{array}$ & $\begin{array}{c}0.001 \\
(0.002)\end{array}$ & $\begin{array}{c}0.0012 \\
(0.0017)\end{array}$ & $\begin{array}{c}0.0013 \\
(0.0018)\end{array}$ \\
\hline January 20-23 (14-17 Days After Capitol Riot) & $\begin{array}{c}0.0010 \\
(0.0017)\end{array}$ & $\begin{array}{c}0.0011 \\
(0.0018)\end{array}$ & $\begin{array}{c}0.0010 \\
(0.0019)\end{array}$ & $\begin{array}{c}-0.000 \\
(0.002)\end{array}$ & $\begin{array}{c}0.0002 \\
(0.0016)\end{array}$ & $\begin{array}{c}0.0001 \\
(0.0017)\end{array}$ \\
\hline January 24-26 (18-20 Days After Capitol Riot) & $\begin{array}{c}0.0020 \\
(0.0020)\end{array}$ & $\begin{array}{c}0.0022 \\
(0.0020)\end{array}$ & $\begin{array}{c}0.0021 \\
(0.0022)\end{array}$ & $\begin{array}{c}0.001 \\
(0.002)\end{array}$ & $\begin{array}{c}0.0016 \\
(0.0020)\end{array}$ & $\begin{array}{c}0.0015 \\
(0.0022)\end{array}$ \\
\hline January 27+ (21+ Days After Capitol Riot) & $\begin{array}{c}0.0022 \\
(0.0022)\end{array}$ & $\begin{array}{c}0.0024 \\
(0.0023)\end{array}$ & $\begin{array}{l}0.0023 \\
(0.0024)\end{array}$ & $\begin{array}{c}0.001 \\
(0.002)\end{array}$ & $\begin{array}{c}0.0012 \\
(0.0023)\end{array}$ & $\begin{array}{c}0.0011 \\
(0.0024)\end{array}$ \\
\hline $\begin{array}{l}\text { Observable Policy \& Testing Controls } \\
\text { State Capitol Counties Omitted } \\
\text { N }\end{array}$ & $\begin{array}{c}\mathrm{N} \\
\mathrm{N} \\
125,400\end{array}$ & $\begin{array}{c}\mathrm{Y} \\
\mathrm{N} \\
125,400\end{array}$ & $\begin{array}{c}\mathrm{Y} \\
\mathrm{Y} \\
123,400\end{array}$ & $\begin{array}{c}\mathrm{N} \\
\mathrm{N} \\
125,400\end{array}$ & $\begin{array}{c}\mathrm{Y} \\
\mathrm{N} \\
125,400\end{array}$ & $\begin{array}{c}\mathrm{Y} \\
\mathrm{Y} \\
123,400\end{array}$ \\
\hline
\end{tabular}

* Significant at the $10 \%$ level, ** Significant at the $5 \%$ level, *** Significant at the $1 \%$ level

Note: Standard errors are clustered at the state level. All estimates include county and day fixed effects as well as county specific linear time trend 
Table 5. Heterogeneity in the Effects of the Capitol Riot on Daily Rate of Cumulative COVID-19 Case Growth, by Mitigation Policies in Home Resident County

\begin{tabular}{|c|c|c|c|c|}
\hline \multirow{4}{*}{ Counties with High Inflow } & \multicolumn{2}{|c|}{ Absolute Inflow } & \multicolumn{2}{|c|}{ Relative Inflow } \\
\hline & (1) & (2) & (3) & (4) \\
\hline & $\begin{array}{c}\text { No } \\
\text { Mitigation }\end{array}$ & $\begin{array}{c}\text { Mitigation } \\
\text { Policies }\end{array}$ & $\begin{array}{c}\text { No } \\
\text { Mitigation } \\
\end{array}$ & $\begin{array}{c}\text { Mitigation } \\
\text { Policies }\end{array}$ \\
\hline & & & & \\
\hline January 6-8 (0-2 Days After Capitol Riot) & $\begin{array}{l}-0.0007 \\
(0.0010)\end{array}$ & $\begin{array}{c}-0.0024 \\
(0.0017)\end{array}$ & $\begin{array}{c}0.0016 \\
(0.0010)\end{array}$ & $\begin{array}{c}0.0073 * * * \\
(0.0016)\end{array}$ \\
\hline January 9-13 (3-7 Days After Capitol Riot) & $\begin{array}{l}0.0040^{*} \\
(0.0012)\end{array}$ & $\begin{array}{c}0.0039 \\
(0.0020)\end{array}$ & $\begin{array}{c}0.0066^{* * *} \\
(0.0018)\end{array}$ & $\begin{array}{c}0.0005 \\
(0.0012)\end{array}$ \\
\hline January 14-15 (8-9 Days After Capitol Riot) & $\begin{array}{c}0.0034 \\
(0.0018)\end{array}$ & $\begin{array}{l}0.0073 * \\
(0.0035)\end{array}$ & $\begin{array}{l}0.0067 * * \\
(0.0019)\end{array}$ & $\begin{array}{c}0.0022 \\
(0.0017)\end{array}$ \\
\hline January 16-19 (10-13 Days After Capitol Riot) & $\begin{array}{l}0.0124 * \\
(0.0035)\end{array}$ & $\begin{array}{c}0.0053 \\
(0.0048)\end{array}$ & $\begin{array}{c}0.0128 * * * \\
(0.0027)\end{array}$ & $\begin{array}{l}-0.0031 \\
(0.0018)\end{array}$ \\
\hline January 20-23 (14-17 Days After Capitol Riot) & $\begin{array}{c}0.0046 \\
(0.0034)\end{array}$ & $\begin{array}{c}0.0063 \\
(0.0033)\end{array}$ & $\begin{array}{c}0.0096 * * \\
(0.0031)\end{array}$ & $\begin{array}{l}-0.0035 \\
(0.0031)\end{array}$ \\
\hline January 24-26 (18-20 Days After Capitol Riot) & $\begin{array}{l}0.0112 * \\
(0.0042)\end{array}$ & $\begin{array}{c}0.0087 \\
(0.0055)\end{array}$ & $\begin{array}{c}0.0138 * * * \\
(0.0035)\end{array}$ & $\begin{array}{l}-0.0041 \\
(0.0027)\end{array}$ \\
\hline $\begin{array}{l}\text { January 27+ (21+ Days After Capitol Riot) } \\
\text { Counties with Moderate- High Inflow }\end{array}$ & $\begin{array}{c}0.0090 \\
(0.0050)\end{array}$ & $\begin{array}{c}0.0090 \\
(0.0061)\end{array}$ & $\begin{array}{c}0.0144 * * \\
(0.0041)\end{array}$ & $\begin{array}{l}-0.0021 \\
(0.0038)\end{array}$ \\
\hline January 6-8 (0-2 Days After Capitol Riot) & $\begin{array}{c}0.0003 \\
(0.0011)\end{array}$ & $\begin{array}{l}-0.0011 \\
(0.0017)\end{array}$ & $\begin{array}{l}-0.0009 \\
(0.0019)\end{array}$ & $\begin{array}{c}0.0011 \\
(0.0014)\end{array}$ \\
\hline January 9-13 (3-7 Days After Capitol Riot) & $\begin{array}{c}0.0002 \\
(0.0011)\end{array}$ & $\begin{array}{c}0.0007 \\
(0.0015)\end{array}$ & $\begin{array}{c}0.0011 \\
(0.0022)\end{array}$ & $\begin{array}{c}0.0013 \\
(0.0013)\end{array}$ \\
\hline January 14-15 (8-9 Days After Capitol Riot) & $\begin{array}{l}-0.0003 \\
(0.0016)\end{array}$ & $\begin{array}{c}0.0004 \\
(0.0016)\end{array}$ & $\begin{array}{c}0.0013 \\
(0.0022)\end{array}$ & $\begin{array}{c}0.0007 \\
(0.0022)\end{array}$ \\
\hline January 16-19 (10-13 Days After Capitol Riot) & $\begin{array}{l}-0.0010 \\
(0.0028)\end{array}$ & $\begin{array}{c}0.0021 \\
(0.0019)\end{array}$ & $\begin{array}{c}0.0030 \\
(0.0032)\end{array}$ & $\begin{array}{c}0.0023 \\
(0.0022)\end{array}$ \\
\hline January 20-23 (14-17 Days After Capitol Riot) & $\begin{array}{l}-0.0016 \\
(0.0027)\end{array}$ & $\begin{array}{c}0.0012 \\
(0.0019)\end{array}$ & $\begin{array}{c}0.0030 \\
(0.0030)\end{array}$ & $\begin{array}{c}0.0018 \\
(0.0032)\end{array}$ \\
\hline January 24-26 (18-20 Days After Capitol Riot) & $\begin{array}{l}-0.0013 \\
(0.0035)\end{array}$ & $\begin{array}{c}0.0031 \\
(0.0026)\end{array}$ & $\begin{array}{c}0.0041 \\
(0.0038)\end{array}$ & $\begin{array}{c}0.0030 \\
(0.0029)\end{array}$ \\
\hline January 27+ (21+ Days After Capitol Riot) & $\begin{array}{c}-0.0022 \\
(0.0039)\end{array}$ & $\begin{array}{c}0.0032 \\
(0.0029)\end{array}$ & $\begin{array}{c}0.0050 \\
(0.0043)\end{array}$ & $\begin{array}{c}0.0027 \\
(0.0039)\end{array}$ \\
\hline Counties with Moderate Inflow & & & & \\
\hline January 6-8 (0-2 Days After Capitol Riot) & $\begin{array}{l}-0.0007 \\
(0.0012)\end{array}$ & $\begin{array}{l}-0.0030 \\
(0.0017)\end{array}$ & $\begin{array}{c}-0.0020 \\
(0.0024)\end{array}$ & $\begin{array}{c}0.0009 \\
(0.0013)\end{array}$ \\
\hline January 9-13 (3-7 Days After Capitol Riot) & $\begin{array}{l}-0.0015 \\
(0.0017)\end{array}$ & $\begin{array}{l}-0.0008 \\
(0.0017)\end{array}$ & $\begin{array}{c}-0.0010 \\
(0.0023)\end{array}$ & $\begin{array}{c}0.0012 \\
(0.0013)\end{array}$ \\
\hline January 14-15 (8-9 Days After Capitol Riot) & $\begin{array}{c}-0.0031 \\
(0.0026)\end{array}$ & $\begin{array}{c}-0.0025 \\
(0.0018)\end{array}$ & $\begin{array}{c}-0.0019 \\
(0.0023)\end{array}$ & $\begin{array}{c}0.0001 \\
(0.0026)\end{array}$ \\
\hline January 16-19 (10-13 Days After Capitol Riot) & $\begin{array}{l}-0.0044 \\
(0.0038)\end{array}$ & $\begin{array}{c}-0.0004 \\
(0.0019)\end{array}$ & $\begin{array}{c}-0.0003 \\
(0.0025)\end{array}$ & $\begin{array}{c}0.0015 \\
(0.0025)\end{array}$ \\
\hline
\end{tabular}




\begin{tabular}{|c|c|c|c|c|}
\hline January 20-23 (14-17 Days After Capitol Riot) & $\begin{array}{l}-0.0040 \\
(0.0037)\end{array}$ & $\begin{array}{l}-0.0018 \\
(0.0019)\end{array}$ & $\begin{array}{c}-0.0005 \\
(0.0025)\end{array}$ & $\begin{array}{c}0.0004 \\
(0.0038)\end{array}$ \\
\hline January 24-26 (18-20 Days After Capitol Riot) & $\begin{array}{l}-0.0045 \\
(0.0048)\end{array}$ & $\begin{array}{l}-0.0007 \\
(0.0020)\end{array}$ & $\begin{array}{c}0.0003 \\
(0.0028)\end{array}$ & $\begin{array}{c}0.0017 \\
(0.0037)\end{array}$ \\
\hline January 27+ (21+ Days After Capitol Riot) & $\begin{array}{l}-0.0056 \\
(0.0055)\end{array}$ & $\begin{array}{l}-0.0015 \\
(0.0022)\end{array}$ & $\begin{array}{c}0.0000 \\
(0.0028)\end{array}$ & $\begin{array}{c}0.0006 \\
(0.0052)\end{array}$ \\
\hline \multicolumn{5}{|l|}{ Counties with Low Inflow } \\
\hline January 6-8 (0-2 Days After Capitol Riot) & $\begin{array}{c}0.0008 \\
(0.0011)\end{array}$ & $\begin{array}{l}-0.0009 \\
(0.0013)\end{array}$ & $\begin{array}{l}-0.0023 \\
(0.0012)\end{array}$ & $\begin{array}{l}-0.0007 \\
(0.0015)\end{array}$ \\
\hline January 9-13 (3-7 Days After Capitol Riot) & $\begin{array}{c}0.0003 \\
(0.0005)\end{array}$ & $\begin{array}{c}0.0007 \\
(0.0015)\end{array}$ & $\begin{array}{l}-0.0006 \\
(0.0014)\end{array}$ & $\begin{array}{c}0.0015 \\
(0.0017)\end{array}$ \\
\hline January 14-15 (8-9 Days After Capitol Riot) & $\begin{array}{l}-0.0010 \\
(0.0009)\end{array}$ & $\begin{array}{l}-0.0000 \\
(0.0016)\end{array}$ & $\begin{array}{l}-0.0012 \\
(0.0019)\end{array}$ & $\begin{array}{c}0.0003 \\
(0.0018)\end{array}$ \\
\hline January 16-19 (10-13 Days After Capitol Riot) & $\begin{array}{l}-0.0011 \\
(0.0013)\end{array}$ & $\begin{array}{c}0.0015 \\
(0.0017)\end{array}$ & $\begin{array}{l}-0.0002 \\
(0.0021)\end{array}$ & $\begin{array}{c}0.0018 \\
(0.0019)\end{array}$ \\
\hline January 20-23 (14-17 Days After Capitol Riot) & $\begin{array}{l}-0.0015 \\
(0.0013)\end{array}$ & $\begin{array}{c}0.0012 \\
(0.0019)\end{array}$ & $\begin{array}{l}-0.0009 \\
(0.0020)\end{array}$ & $\begin{array}{c}0.0007 \\
(0.0023)\end{array}$ \\
\hline January 24-26 (18-20 Days After Capitol Riot) & $\begin{array}{c}-0.0016 \\
(0.0017)\end{array}$ & $\begin{array}{c}0.0024 \\
(0.0022)\end{array}$ & $\begin{array}{c}0.0002 \\
(0.0026)\end{array}$ & $\begin{array}{c}0.0023 \\
(0.0023)\end{array}$ \\
\hline January 27+ (21+ Days After Capitol Riot) & $\begin{array}{l}-0.0026 \\
(0.0021)\end{array}$ & $\begin{array}{c}0.0027 \\
(0.0024)\end{array}$ & $\begin{array}{l}-0.0002 \\
(0.0029)\end{array}$ & $\begin{array}{c}0.0022 \\
(0.0031)\end{array}$ \\
\hline $\begin{array}{l}\text { Restrictions on Restaurants or Bars? } \\
\mathrm{N}\end{array}$ & $\underset{19,440}{\mathrm{~N}}$ & $\begin{array}{c}\mathrm{Y} \\
105,960\end{array}$ & $\begin{array}{c}\mathrm{N} \\
108,360\end{array}$ & $\begin{array}{c}\mathrm{Y} \\
17,040\end{array}$ \\
\hline
\end{tabular}

* Significant at the $10 \%$ level, ** Significant at the 5\% level, *** Significant at the $1 \%$ level

Note: Standard errors are clustered at the state level. All estimates include county and day fixed effects as well as county specific linear time trend. For columns (1) and (2), the mitigation policy under study is whether there was any restriction on indoor dining at restaurants or bars. For columns (3) and (4), where we have more mitigation policy variation, the mitigation policy under study is whether there were full indoor dining/drinking bans at bars and some capacity restriction or full indoor dining ban at restaurants. 
Appendix Figure 1. Distribution of Home Counties for Smartphones that "Pinged" in the Protest CBG Cluster on January 4, 6, and 8, 2021: Absolute Measure

Panel (a): January 4 (Before Riot)

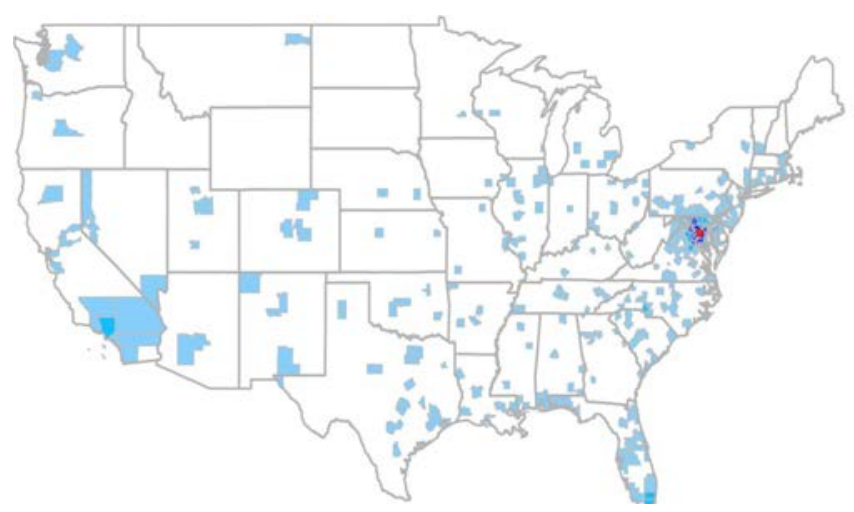

Absolute Inflow

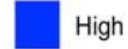

Moderate-High

Moderate-Low

Low

Panel (b): January 6(Day of Riot)
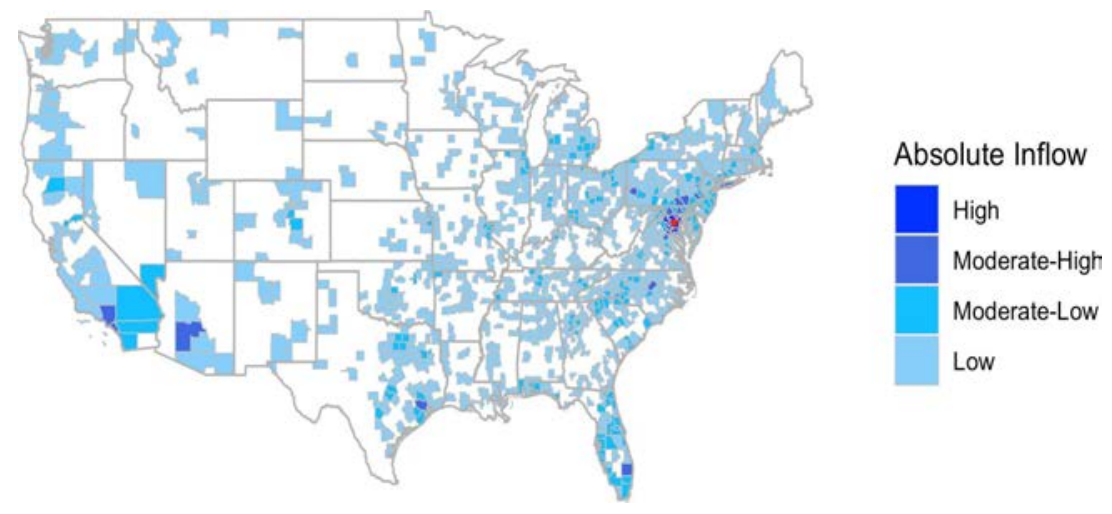

Panel (c): January 8 (After Riot)

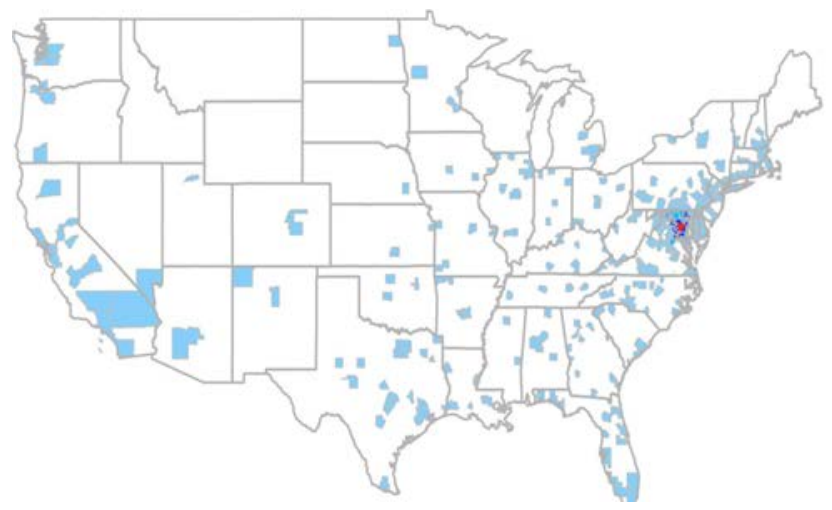

Absolute Inflow

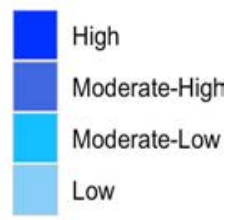




\section{Appendix Table 1. Difference-in-Differences Estimates of Effect of The Capitol Riot on Log Smartphone Pings in Treatment and Border Census Block Groups}

(1)

(4)

Total Smartphone Pings

Non-Resident Smartphone Pings

\begin{tabular}{lcccc}
\cline { 2 - 5 } January 6 & $0.564 * *$ & $0.354^{* *}$ & $0.638^{* *}$ & 0.381 \\
& {$[\mathrm{p}=0.0231]$} & {$[\mathrm{p}=0.044]$} & {$[\mathrm{p}=0.0324]$} & {$[\mathrm{p}=0.1065]$} \\
January 7+ & 0.044 & -0.376 & 0.029 & -0.485 \\
& {$[\mathrm{p}=0.2731]$} & {$[\mathrm{p}=0.9259]$} & {$[\mathrm{p}=0.3935]$} & {$[\mathrm{p}=0.9051]$} \\
Observations & 4,950 & 4,950 & 4,950 & 4,950 \\
& & & & \\
\cline { 2 - 5 } CBG Linear Time Trend? & No & Yes & No & Yes \\
\hline
\end{tabular}

***Significant at $1 \%$ level **at $5 \%$ level *at $10 \%$ level

Notes: Estimates are generated using ordinary least squares. All models include cluster and day fixed effects.

Permutation based p-value is reported inside the bracket. 


\section{Appendix Table 2. Estimated Effect of Capitol Riot on Inverse Hyperbolic Sine of Daily COVID-19 Cases}

\begin{tabular}{|c|c|c|}
\hline & $\begin{array}{c}\text { Absolute } \\
\text { Inflow } \\
(1)\end{array}$ & $\begin{array}{c}\text { Relative } \\
\text { Inflow } \\
\text { (2) }\end{array}$ \\
\hline \multicolumn{3}{|l|}{ Counties with High Inflow } \\
\hline \multirow[t]{2}{*}{ January 6-8 (0-2 Days After Capitol Riot) } & -0.421 & -0.136 \\
\hline & $(0.32)$ & $(0.114)$ \\
\hline \multirow[t]{2}{*}{ January 9-13 (3-7 Days After Capitol Riot) } & 0.389 & 0.257 \\
\hline & $(0.252)$ & $(0.146)$ \\
\hline \multirow[t]{2}{*}{ January 14-15 (8-9 Days After Capitol Riot) } & 0.318 & 0.168 \\
\hline & $(0.293)$ & $(0.194)$ \\
\hline \multirow[t]{2}{*}{ January 16-19 (10-13 Days After Capitol Riot) } & 0.859 & 0.556 \\
\hline & $(0.545)$ & $(0.306)$ \\
\hline \multirow[t]{2}{*}{ January 20-23 (14-17 Days After Capitol Riot) } & 0.534 & 0.255 \\
\hline & $(0.421)$ & $(0.277)$ \\
\hline \multirow[t]{2}{*}{ January 24-26 (18-20 Days After Capitol Riot) } & 1.119 & 0.656 \\
\hline & $(0.559)$ & $(0.39)$ \\
\hline \multirow[t]{2}{*}{ January 27+ (21+ Days After Capitol Riot) } & 0.916 & 0.589 \\
\hline & $(0.683)$ & $(0.431)$ \\
\hline \multicolumn{3}{|l|}{ Counties with Moderate- High Inflow } \\
\hline \multirow[t]{2}{*}{ January 6-8 (0-2 Days After Capitol Riot) } & -0.054 & 0.03 \\
\hline & $(0.16)$ & $(0.054)$ \\
\hline \multirow[t]{2}{*}{ January 9-13 (3-7 Days After Capitol Riot) } & 0.079 & 0.139 \\
\hline & $(0.252)$ & $(0.082)$ \\
\hline \multirow[t]{2}{*}{ January 14-15 (8-9 Days After Capitol Riot) } & 0.126 & 0.178 \\
\hline & $(0.249)$ & $(0.094)$ \\
\hline \multirow[t]{2}{*}{ January 16-19 (10-13 Days After Capitol Riot) } & 0.058 & 0.225 \\
\hline & $(0.492)$ & $(0.196)$ \\
\hline \multirow[t]{2}{*}{ January 20-23 (14-17 Days After Capitol Riot) } & -0.017 & 0.193 \\
\hline & $(0.499)$ & $(0.177)$ \\
\hline \multirow[t]{2}{*}{ January 24-26 (18-20 Days After Capitol Riot) } & 0.164 & 0.318 \\
\hline & $(0.653)$ & $(0.223)$ \\
\hline \multirow[t]{2}{*}{ January 27+ (21+ Days After Capitol Riot) } & 0.048 & 0.295 \\
\hline & $(0.762)$ & $(0.272)$ \\
\hline \multicolumn{3}{|l|}{ Counties with Moderate Inflow } \\
\hline \multirow[t]{2}{*}{ January 6-8 (0-2 Days After Capitol Riot) } & -0.117 & 0.025 \\
\hline & $(0.075)$ & $(0.067)$ \\
\hline \multirow[t]{2}{*}{ January 9-13 (3-7 Days After Capitol Riot) } & -0.127 & -0.033 \\
\hline & $(0.138)$ & $(0.088)$ \\
\hline \multirow[t]{2}{*}{ January 14-15 (8-9 Days After Capitol Riot) } & -0.063 & 0.047 \\
\hline & $(0.145)$ & $(0.092)$ \\
\hline \multirow[t]{2}{*}{ January 16-19 (10-13 Days After Capitol Riot) } & -0.268 & -0.172 \\
\hline & $(0.271)$ & $(0.202)$ \\
\hline \multirow[t]{2}{*}{ January 20-23 (14-17 Days After Capitol Riot) } & -0.354 & -0.125 \\
\hline & $(0.294)$ & $(0.17)$ \\
\hline
\end{tabular}




\begin{tabular}{lcc} 
January 24-26 (18-20 Days After Capitol Riot) & -0.261 & -0.166 \\
& $(0.348)$ & $(0.254)$ \\
January 27+ (21+ Days After Capitol Riot) & -0.469 & -0.214 \\
& $(0.435)$ & $(0.278)$ \\
Counties with Low Inflow & & \\
\hline January 6-8 (0-2 Days After Capitol Riot) & 0.025 & -0.086 \\
& $(0.039)$ & $(0.048)$ \\
January 9-13 (3-7 Days After Capitol Riot) & 0.058 & -0.096 \\
& $(0.065)$ & $(0.103)$ \\
January 14-15 (8-9 Days After Capitol Riot) & 0.109 & -0.036 \\
& $(0.088)$ & $(0.126)$ \\
January 16-19 (10-13 Days After Capitol Riot) & 0.009 & -0.324 \\
& $(0.138)$ & $(0.198)$ \\
January 20-23 (14-17 Days After Capitol Riot) & 0.016 & -0.35 \\
& $(0.136)$ & $(0.206)$ \\
January 24-26 (18-20 Days After Capitol Riot) & 0.074 & -0.268 \\
& $(0.166)$ & $(0.235)$ \\
January 27+ (21+ Days After Capitol Riot) & 0.05 & -0.406 \\
& $(0.203)$ & $(0.295)$ \\
N & 125,400 & 125,400 \\
\hline
\end{tabular}

* Significant at the $10 \%$ level, ** Significant at the $5 \%$ level, *** Significant at the $1 \%$ level Note: Standard errors are clustered at the state level. All estimates include county and day fixed effects as well as county specific linear time trend. 
Appendix Table 3. Sensitivity of Estimates for Higher-Inflow Counties Shown in Columns (3) and (6) of Table 4 to Controls for Census Division-Specific Day Effects

\begin{tabular}{|c|c|c|}
\hline & $\begin{array}{c}\text { Absolute } \\
\text { Inflow } \\
(1)\end{array}$ & $\begin{array}{c}\text { Relative } \\
\text { Inflow } \\
(2)\end{array}$ \\
\hline \multicolumn{3}{|l|}{ Counties with High Inflow } \\
\hline January 6-8 (0-2 Days After Capitol Riot) & $\begin{array}{c}-0.002 \\
(0.002)\end{array}$ & $\begin{array}{c}0.002 \\
(0.002)\end{array}$ \\
\hline January 9-13 (3-7 Days After Capitol Riot) & $\begin{array}{c}0.005 \\
(0.003)\end{array}$ & $\begin{array}{l}0.006 * \\
(0.002)\end{array}$ \\
\hline January 14-15 (8-9 Days After Capitol Riot) & $\begin{array}{c}0.007 \\
(0.005)\end{array}$ & $\begin{array}{c}0.005 * \\
(0.003)\end{array}$ \\
\hline January 16-19 (10-13 Days After Capitol Riot) & $\begin{array}{c}0.009 \\
(0.005)\end{array}$ & $\begin{array}{c}0.009 * * \\
(0.003)\end{array}$ \\
\hline January 20-23 (14-17 Days After Capitol Riot) & $\begin{array}{c}0.008 \\
(0.005)\end{array}$ & $\begin{array}{c}0.006 \\
(0.003)\end{array}$ \\
\hline January 24-26 (18-20 Days After Capitol Riot) & $\begin{array}{c}0.012 \\
(0.007)\end{array}$ & $\begin{array}{c}0.010^{* *} \\
(0.004)\end{array}$ \\
\hline January 27+ (21+ Days After Capitol Riot) & $\begin{array}{c}0.012 \\
(0.008)\end{array}$ & $\begin{array}{l}0.009 * \\
(0.004)\end{array}$ \\
\hline \multicolumn{3}{|l|}{ Counties with Moderate- High Inflow } \\
\hline January 6-8 (0-2 Days After Capitol Riot) & $\begin{array}{l}-0.000 \\
(0.001)\end{array}$ & $\begin{array}{l}-0.001 \\
(0.001)\end{array}$ \\
\hline January 9-13 (3-7 Days After Capitol Riot) & $\begin{array}{c}0.001 \\
(0.001)\end{array}$ & $\begin{array}{c}0.001 \\
(0.002)\end{array}$ \\
\hline January 14-15 (8-9 Days After Capitol Riot) & $\begin{array}{c}0.000 \\
(0.001)\end{array}$ & $\begin{array}{c}0.000 \\
(0.002)\end{array}$ \\
\hline January 16-19 (10-13 Days After Capitol Riot) & $\begin{array}{c}0.002 \\
(0.001)\end{array}$ & $\begin{array}{c}0.001 \\
(0.002)\end{array}$ \\
\hline January 20-23 (14-17 Days After Capitol Riot) & $\begin{array}{c}0.001 \\
(0.002)\end{array}$ & $\begin{array}{c}0.001 \\
(0.002)\end{array}$ \\
\hline January 24-26 (18-20 Days After Capitol Riot) & $\begin{array}{c}0.002 \\
(0.002)\end{array}$ & $\begin{array}{c}0.002 \\
(0.003)\end{array}$ \\
\hline January 27+ (21+ Days After Capitol Riot) & $\begin{array}{c}0.002 \\
(0.002)\end{array}$ & $\begin{array}{c}0.003 \\
(0.003)\end{array}$ \\
\hline Counties with Moderate Inflow & & \\
\hline January 6-8 (0-2 Days After Capitol Riot) & $\begin{array}{c}-0.002 * * \\
(0.001)\end{array}$ & $\begin{array}{c}-0.001 \\
(0.001)\end{array}$ \\
\hline January 9-13 (3-7 Days After Capitol Riot) & $\begin{array}{l}-0.000 \\
(0.001)\end{array}$ & $\begin{array}{c}-0.000 \\
(0.001)\end{array}$ \\
\hline January 14-15 (8-9 Days After Capitol Riot) & $\begin{array}{c}-0.002 \\
(0.001)\end{array}$ & $\begin{array}{l}-0.001 \\
(0.001)\end{array}$ \\
\hline January 16-19 (10-13 Days After Capitol Riot) & $\begin{array}{c}-0.000 \\
(0.002)\end{array}$ & $\begin{array}{c}-0.000 \\
(0.001)\end{array}$ \\
\hline January 20-23 (14-17 Days After Capitol Riot) & $\begin{array}{c}-0.001 \\
(0.002)\end{array}$ & $\begin{array}{c}-0.001 \\
(0.001)\end{array}$ \\
\hline January 24-26 (18-20 Days After Capitol Riot) & $\begin{array}{c}-0.000 \\
(0.002)\end{array}$ & $\begin{array}{c}0.000 \\
(0.001)\end{array}$ \\
\hline
\end{tabular}


* Significant at the $10 \%$ level, ** Significant at the 5\% level, *** Significant at the $1 \%$ level Note: Standard errors are clustered at the state level. All estimates include county and day fixed effects as well as county specific linear time trend as well as observable policy controls. 
Appendix Table 4. Unweighted Estimates of the Effect of the Capitol Riot on Daily Rate of Cumulative COVID-19 Case Growth

\begin{tabular}{|c|c|c|}
\hline & $\begin{array}{c}\text { Absolute } \\
\text { Inflow } \\
(1)\end{array}$ & $\begin{array}{l}\text { Relative } \\
\text { Inflow } \\
\text { (2) }\end{array}$ \\
\hline \multicolumn{3}{|l|}{ Counties with High Inflow } \\
\hline January 6-8 (0-2 Days After Capitol Riot) & $\begin{array}{l}-0.001 \\
(0.001)\end{array}$ & $\begin{array}{c}0.002 \\
(0.001)\end{array}$ \\
\hline January 9-13 (3-7 Days After Capitol Riot) & $\begin{array}{c}0.006^{* *} \\
(0.002)\end{array}$ & $\begin{array}{c}0.006^{* *} \\
(0.002)\end{array}$ \\
\hline January 14-15 (8-9 Days After Capitol Riot) & $\begin{array}{l}0.006^{*} \\
(0.002)\end{array}$ & $\begin{array}{l}0.007^{*} \\
(0.003)\end{array}$ \\
\hline January 16-19 (10-13 Days After Capitol Riot) & $\begin{array}{c}0.010^{*} \\
(0.004)\end{array}$ & $\begin{array}{l}0.009^{*} \\
(0.004)\end{array}$ \\
\hline January 20-23 (14-17 Days After Capitol Riot) & $\begin{array}{c}0.008 * * \\
(0.002)\end{array}$ & $\begin{array}{c}0.007 \\
(0.004)\end{array}$ \\
\hline January 24-26 (18-20 Days After Capitol Riot) & $\begin{array}{c}0.012 * * \\
(0.004)\end{array}$ & $\begin{array}{c}0.010 \\
(0.006)\end{array}$ \\
\hline January 27+ (21+ Days After Capitol Riot) & $\begin{array}{l}0.011^{*} \\
(0.004)\end{array}$ & $\begin{array}{c}0.012 \\
(0.007)\end{array}$ \\
\hline Counties with Moderate- High Inflow & & \\
\hline January 6-8 (0-2 Days After Capitol Riot) & $\begin{array}{c}-0.002 \\
(0.002)\end{array}$ & $\begin{array}{c}0.000 \\
(0.001)\end{array}$ \\
\hline January 9-13 (3-7 Days After Capitol Riot) & $\begin{array}{c}0.000 \\
(0.002)\end{array}$ & $\begin{array}{c}0.001 \\
(0.001)\end{array}$ \\
\hline January 14-15 (8-9 Days After Capitol Riot) & $\begin{array}{c}0.001 \\
(0.002)\end{array}$ & $\begin{array}{c}0.001 \\
(0.001)\end{array}$ \\
\hline January 16-19 (10-13 Days After Capitol Riot) & $\begin{array}{c}0.003 \\
(0.003)\end{array}$ & $\begin{array}{c}0.002 \\
(0.002)\end{array}$ \\
\hline January 20-23 (14-17 Days After Capitol Riot) & $\begin{array}{c}0.002 \\
(0.003)\end{array}$ & $\begin{array}{c}0.001 \\
(0.001)\end{array}$ \\
\hline January 24-26 (18-20 Days After Capitol Riot) & $\begin{array}{c}0.005 \\
(0.003)\end{array}$ & $\begin{array}{c}0.002 \\
(0.002)\end{array}$ \\
\hline January 27+ (21+ Days After Capitol Riot) & $\begin{array}{c}0.005 \\
(0.004)\end{array}$ & $\begin{array}{c}0.003 \\
(0.002)\end{array}$ \\
\hline Counties with Moderate Inflow & & \\
\hline January 6-8 (0-2 Days After Capitol Riot) & $\begin{array}{l}-0.002 \\
(0.002)\end{array}$ & $\begin{array}{l}-0.001 \\
(0.002)\end{array}$ \\
\hline January 9-13 (3-7 Days After Capitol Riot) & $\begin{array}{c}0.000 \\
(0.002)\end{array}$ & $\begin{array}{c}-0.001 \\
(0.001)\end{array}$ \\
\hline January 14-15 (8-9 Days After Capitol Riot) & $\begin{array}{c}0.001 \\
(0.002)\end{array}$ & $\begin{array}{l}-0.001 \\
(0.002)\end{array}$ \\
\hline January 16-19 (10-13 Days After Capitol Riot) & $\begin{array}{c}0.001 \\
(0.002)\end{array}$ & $\begin{array}{l}-0.000 \\
(0.002)\end{array}$ \\
\hline January 20-23 (14-17 Days After Capitol Riot) & $\begin{array}{c}0.000 \\
(0.002)\end{array}$ & $\begin{array}{l}-0.001 \\
(0.002)\end{array}$ \\
\hline January 24-26 (18-20 Days After Capitol Riot) & $\begin{array}{c}0.002 \\
(0.002)\end{array}$ & $\begin{array}{l}-0.000 \\
(0.002)\end{array}$ \\
\hline January 27+ (21+ Days After Capitol Riot) & 0.002 & -0.000 \\
\hline
\end{tabular}


Counties with Low Inflow

\begin{tabular}{lcc}
\hline January 6-8 (0-2 Days After Capitol Riot) & -0.000 & -0.002 \\
& $(0.001)$ & $(0.001)$ \\
January 9-13 (3-7 Days After Capitol Riot) & 0.001 & 0.000 \\
& $(0.001)$ & $(0.001)$ \\
January 14-15 (8-9 Days After Capitol Riot) & 0.000 & -0.000 \\
& $(0.001)$ & $(0.001)$ \\
January 16-19 (10-13 Days After Capitol Riot) & 0.001 & 0.000 \\
& $(0.001)$ & $(0.001)$ \\
January 20-23 (14-17 Days After Capitol Riot) & 0.000 & -0.000 \\
& $(0.001)$ & $(0.001)$ \\
January 24-26 (18-20 Days After Capitol Riot) & 0.001 & 0.001 \\
& $(0.001)$ & $(0.001)$ \\
January 27+ (21+ Days After Capitol Riot) & 0.002 & 0.001 \\
& $(0.001)$ & $(0.002)$ \\
& & \\
N & 125,400 & 125,400 \\
\hline * Significant at the 10\% level, ** Significant at the 5\% level, *** Significant at the 1\% level \\
Note: Standard errors are clustered at the state level. All estimates include county and day fixed \\
effects as well as county specific linear time trend.
\end{tabular}




\section{Appendix Table 5A. Synthetic Control Estimates of Effect of Capitol Riot on Cumulative COVID- 19 Deaths Per 100,000 Population}

\begin{tabular}{|c|c|c|c|c|}
\hline \multirow[b]{4}{*}{ Full Capitol Riot Treatment Effect (1/6 - 1/21) } & \multicolumn{3}{|c|}{ Log (Deaths Per 100,000) } & \multirow{2}{*}{$\begin{array}{l}\text { Deaths Per } \\
100,000 \\
\text { (4) }\end{array}$} \\
\hline & (1) & (2) & (3) & \\
\hline & \multicolumn{4}{|c|}{ Panel I: Full Post-Treatment Period } \\
\hline & -0.055 & -0.092 & 0.006 & -11.514 \\
\hline P-Value & {$[0.257]$} & [0.239] & {$[0.569]$} & {$[0.651]$} \\
\hline One Sided P-Value & {$[0.174]$} & {$[0.138]$} & {$[0.752]$} & [0.339] \\
\hline \multirow[t]{2}{*}{ Pre-Treatment Mean of DV } & 4.71 & 4.71 & 4.71 & 111.48 \\
\hline & \multicolumn{4}{|c|}{ Panel II: Lagged Post-Treatment Windows } \\
\hline $\begin{array}{l}\text { First Post-Treatment Window (1/6-1/12) } \\
\text { P-Value } \\
\text { One Sided P-Value }\end{array}$ & $\begin{array}{l}-0.029 \\
{[0.183]} \\
{[0.147]}\end{array}$ & $\begin{array}{c}-0.05 \\
{[0.248]} \\
{[0.156]}\end{array}$ & $\begin{array}{l}-0.004 \\
{[0.606]} \\
{[0.716]}\end{array}$ & $\begin{array}{l}-2.743 \\
{[0.743]} \\
{[0.385]}\end{array}$ \\
\hline Middle Post-Treatment Window (1/13-1/19) & -0.046 & -0.063 & 0.005 & -14.668 \\
\hline P-Value & {$[0.248]$} & {$[0.321]$} & {$[0.725]$} & {$[0.431]$} \\
\hline One Sided P-Value & {$[0.165]$} & {$[0.165]$} & {$[0.688]$} & [0.239] \\
\hline Longer-Run Post-Treatment Window (1/20+) & -0.071 & -0.124 & 0.011 & -14.135 \\
\hline P-Value & {$[0.266]$} & {$[0.220]$} & [0.523] & [0.615] \\
\hline One Sided P-Value & {$[0.174]$} & {$[0.128]$} & {$[0.752]$} & [0.303] \\
\hline Pre-Treatment Mean of DV & 4.71 & 4.71 & 4.71 & 111.48 \\
\hline \multicolumn{5}{|l|}{ Matching Variables } \\
\hline All Pre-Treatment Days & $\mathrm{Y}$ & $\mathrm{N}$ & $\mathrm{N}$ & $\mathrm{N}$ \\
\hline $\begin{array}{l}\text { Match on 12/28,12/30,1/1,1/3,1/5 Cases } \\
\text { Urbanicity, Pop Density, Testing Trend, } \\
\text { Restaurant/Bar Closure, Pre-1/6 SAH Behavior }\end{array}$ & $\mathrm{N}$ & $\mathrm{Y}$ & $\mathrm{Y}$ & $\mathrm{Y}$ \\
\hline $\begin{array}{l}\text { Match on Stay-at-Home Advisory, Mask } \\
\text { Mandate, Curfew }\end{array}$ & $\mathrm{N}$ & $\mathrm{N}$ & $\mathrm{Y}$ & $\mathrm{Y}$ \\
\hline
\end{tabular}

* Significant at the $10 \%$ level; ** Significant at the 5\% level; *** Significant at the $1 \%$ level Notes: The donor pool is comprised of counties with urbanicity rate above $80 \%$, and excludes counties in border states, as well as counties with greater than 1 home resident that pinged in the census block group of the United States Capitol Building on 1/6. 


\section{Appendix Table 5B. Dose-Response Difference-in-Differences Estimates of the Effect of the Capitol Riot on Daily Rate of Cumulative COVID-19 Deaths}

\section{Absolute Inflow}

(1)

Counties with High Inflow

January 6-8 (0-2 Days After Capitol Riot)
January 9-13 (3-7 Days After Capitol Riot)
January 14-15 (8-9 Days After Capitol Riot)
January 16-19 (10-13 Days After Capitol Riot)
January 20-23 (14-17 Days After Capitol Riot)
January 24-26 (18-20 Days After Capitol Riot)

January 27+ (21+ Days After Capitol Riot)

Counties with Moderate- High Inflow

\begin{tabular}{lcccc}
\hline January 6-8 (0-2 Days After Capitol Riot) & 0.0012 & 0.0013 & -0.0011 & -0.0011 \\
& $(0.0019)$ & $(0.0019)$ & $(0.0018)$ & $(0.0018)$ \\
January 9-13 (3-7 Days After Capitol Riot) & 0.0037 & $0.0039 *$ & 0.0012 & 0.0014 \\
& $(0.0018)$ & $(0.0018)$ & $(0.0017)$ & $(0.0017)$ \\
January 14-15 (8-9 Days After Capitol Riot) & 0.0041 & 0.0045 & 0.0021 & 0.0024 \\
& $(0.0027)$ & $(0.0027)$ & $(0.0024)$ & $(0.0024)$ \\
January 16-19 (10-13 Days After Capitol Riot) & 0.0039 & $0.0043 *$ & 0.0014 & 0.0016 \\
& $(0.0021)$ & $(0.0021)$ & $(0.0030)$ & $(0.0030)$ \\
& 0.005 & 0.0054 & 0.0022 & 0.0025 \\
January 20-23 (14-17 Days After Capitol Riot) & $(0.003)$ & $(0.0030)$ & $(0.0039)$ & $(0.0039)$ \\
& 0.005 & 0.0057 & 0.0019 & 0.0020 \\
January 24-26 (18-20 Days After Capitol Riot) & $(0.003)$ & $(0.0030)$ & $(0.0044)$ & $(0.0045)$ \\
& 0.0065 & 0.0073 & 0.0035 & 0.0037 \\
January 27+ (21+ Days After Capitol Riot) & $(0.0037)$ & $(0.0038)$ & $(0.0054)$ & $(0.0054)$ \\
& & & & -0.0018 \\
Counties with Moderate Inflow & -0.0014 & -0.0013 & -0.0019 & $(0.0018)$ \\
January 6-8 (0-2 Days After Capitol Riot) & $(0.0015)$ & $(0.0015)$ & $(0.0018)$ & 0.0021 \\
January 9-13 (3-7 Days After Capitol Riot) & 0.0017 & 0.0020 & 0.0019 & $(0.0019)$ \\
& $(0.0014)$ & $(0.0014)$ & $(0.0019)$ & 0.0018 \\
January 14-15 (8-9 Days After Capitol Riot) & 0.0024 & 0.0028 & 0.0015 & $(0.0026)$ \\
& $(0.002)$ & $(0.0020)$ & $(0.0026)$ & 0.0029 \\
January 16-19 (10-13 Days After Capitol Riot) & 0.0027 & 0.0031 & 0.0025 & $(0.0032)$ \\
January 20-23 (14-17 Days After Capitol Riot) & $(0.0024)$ & $(0.0025)$ & $(0.0031)$ & 0.0033 \\
& $(0.0027$ & 0.0031 & 0.0029 & $(0.0041)$ \\
January 24-26 (18-20 Days After Capitol Riot) & 0.0038 & $(0.0033)$ & $(0.0040)$ & 0.0042 \\
January 27+ (21+ Days After Capitol Riot) & $(0.0031)$ & 0.0042 & 0.0039 & $(0.0046)$ \\
& 0.0049 & $0.0032)$ & $(0.0045)$ & 0.0059 \\
& $(0.0042)$ & $(0.0043)$ & $(0.0055)$ & $(0.0056)$
\end{tabular}

Relative Inflow

(4)

$\begin{array}{cccc}-0.0008 & -0.0007 & -0.0017 & -0.0016 \\ (0.0019) & (0.0019) & (0.0019) & (0.0019) \\ 0.0033 & 0.0036 & 0.0030 & 0.0032 \\ (0.0023) & (0.0023) & (0.0018) & (0.0018) \\ 0.0052 & 0.0057^{*} & 0.0058 & 0.0061 \\ (0.0028) & (0.0028) & (0.0044) & (0.0044) \\ 0.006 & 0.0064 & 0.0089^{*} & 0.0092^{*} \\ (0.0048) & (0.0048) & (0.0039) & (0.0039) \\ 0.0062 & 0.0067 & 0.0111 & 0.0115 \\ (0.0055) & (0.0056) & (0.0065) & (0.0065) \\ 0.007 & 0.0074 & 0.0100 & 0.0103 \\ (0.0072) & (0.0073) & (0.0059) & (0.0059) \\ 0.0099 & 0.0103 & 0.0145 & 0.0147 \\ (0.0084) & (0.0084) & (0.0077) & (0.0077)\end{array}$

61 
Counties with Low Inflow

\begin{tabular}{lcccc}
\hline January 6-8 (0-2 Days After Capitol Riot) & -0.0011 & -0.0011 & -0.0001 & -0.0000 \\
& $(0.0013)$ & $(0.0013)$ & $(0.0013)$ & $(0.0013)$ \\
January 9-13 (3-7 Days After Capitol Riot) & 0.0013 & 0.0014 & 0.0022 & $0.0025^{*}$ \\
& $(0.0013)$ & $(0.0013)$ & $(0.0011)$ & $(0.0012)$ \\
January 14-15 (8-9 Days After Capitol Riot) & 0.0005 & 0.0008 & 0.0023 & 0.0027 \\
& $(0.002)$ & $(0.0021)$ & $(0.0017)$ & $(0.0017)$ \\
January 16-19 (10-13 Days After Capitol Riot) & 0.0003 & 0.0006 & 0.0020 & 0.0024 \\
& $(0.0031)$ & $(0.0032)$ & $(0.0023)$ & $(0.0024)$ \\
January 20-23 (14-17 Days After Capitol Riot) & 0.0016 & 0.0019 & 0.0029 & 0.0033 \\
& $(0.0032)$ & $(0.0032)$ & $(0.0027)$ & $(0.0027)$ \\
January 24-26 (18-20 Days After Capitol Riot) & 0.002 & 0.0024 & 0.0036 & 0.0041 \\
& $(0.004)$ & $(0.0041)$ & $(0.0030)$ & $(0.0030)$ \\
January 27+ (21+ Days After Capitol Riot) & 0.0024 & 0.0028 & 0.0041 & 0.0046 \\
& $(0.0049)$ & $(0.0049)$ & $(0.0037)$ & $(0.0037)$ \\
Observable Policy \& Testing Controls & & & $\mathrm{N}$ & $\mathrm{N}$ \\
State Capitol Counties Omitted & $\mathrm{N}$ & $\mathrm{Y}$ & $\mathrm{N}$ & $\mathrm{N}$ \\
$\mathrm{N}$ & 125,400 & 125,400 & 125,400 & 125,400 \\
\hline
\end{tabular}

* Significant at the $10 \%$ level, ** Significant at the $5 \%$ level, *** Significant at the $1 \%$ level

Note: Standard errors are clustered at the state level. All estimates include county and day fixed effects as well as county specific linear time trend 